Research Article

\title{
Study on the Creep Behaviors of Interactive Marine-Terrestrial Deposit Soils
}

\author{
Zhen Yan, ${ }^{1}$ Gang Li ${ }^{1},{ }^{2}$ Jinli Zhang, ${ }^{3}$ and Rui Zhang ${ }^{2}$ \\ ${ }^{1}$ Tianjin Research Institute for Water Transport Engineering, Ministry of Transport, Tianjin 300456, China \\ ${ }^{2}$ Shaanxi Key Laboratory of Safety and Durability of Concrete Structures, Xijing University, Xi'an, Shaanxi 710123, China \\ ${ }^{3}$ State Key Laboratory of Coastal and Offshore Engineering, Dalian University of Technology, Dalian, Liaoning 116024, China
}

Correspondence should be addressed to Gang Li; t_bag945@126.com

Received 20 November 2018; Accepted 18 February 2019; Published 7 July 2019

Academic Editor: Giulio Dondi

Copyright (C) 2019 Zhen Yan et al. This is an open access article distributed under the Creative Commons Attribution License, which permits unrestricted use, distribution, and reproduction in any medium, provided the original work is properly cited.

The interactive marine-terrestrial (IMT) deposit soils were formed in the complex depositional environment; their mechanical properties are different from the other deposits. The creep behaviors of Dalian clayey soils were studied according to onedimensional creep tests and drained triaxial creep tests. Based on the creep test results, the empirical model was established to describe the one-dimensional creep behavior and triaxial creep behavior, respectively. The results showed that Dalian deposits have typical nonlinear creep behavior. With the increasing of consolidation pressure, the strain is increased, the stability time is extended, and the demarcation point between primary and secondary consolidation is more obvious. The deposits belong to medium to high secondary compressibility soil, and the secondary consolidation coefficient is decreased with the increasing of consolidation time and increased with consolidation pressure increasing. The ratio between secondary consolidation coefficient and compression index at different depths changes from 0.033 to 0.058 , which conform to Mesri conclusion. Under low deviator stress, the creep processes showed the characteristic of attenuation creep and shear contraction. However, it showed the characteristic of acceleration creep, shear contraction, and shear dilatancy under damage deviator stress. The axial strain rate decreased with the increasing of creep time and increased with the deviator stress increasing, while the deviator stress has little effect on the $m$ values. The tests results agree well with the calculation results, which showed that the creep equation is suitable for describing the creep behaviors of Dalian interactive marine-terrestrial deposits.

\section{Introduction}

The engineering properties of soils are related to their sedimentary environments. Interactive marine-terrestrial (IMT) deposits were formed from historical processes including transgression-regression and the reciprocating movement of coastlines [1]. Compared with typical marine deposits, IMT deposits generally have lower natural water content and void ratios but relatively better mechanical properties (compression index, friction angle, etc.) and more variable physical and mechanical properties. Chen [2] studied the consolidation properties of IMT soft deposits in the Pearl River Delta, analyzed the effects of consolidation on their basic mechanical properties, and proposed a quantitative analysis method that considers the consolidation effect. By examining the physical and mechanical properties of an IMT clay at the Yangtze River estuary, Liu and Shi [3] found that the physical property indices of soil in this region were not consistent with its mechanical property indices, analyzed the reason behind this phenomenon, and proposed a new method for evaluating the engineering properties of this soil type. Zhang et al. [4] analyzed the physical property indices of an IMT clay on the north side of the Yangtze River estuary using principal component analysis and noted unreasonableness in using the liquidity index to determine its consistency. Liu et al. [5] studied the pore pressure response of a PHC (high strength, prestressed concrete pipe piles) composite foundation in the IMT deposits on the north shore of the Yangtze River estuary and found that shallow deposits had relatively high permeability and sensitive excess pore pressure response but that deep deposits had low permeability and excess pore pressure that 
increased with the overlying load. Tuo et al. [6] investigated the engineering properties of Zhanjiang IMT soft clays and noted that under the influence of tectonic movement, these deposits exhibited special sedimentary characteristics due to the coupling action of complex geological stresses and had relatively high structural strength due to aggregation. Shi et al. [7] examined the mechanical properties of natural intermediate deposits on the north shore of the Yangtze River estuary and found that the physical properties of this type of soil were similar to those of soft clays, but the in situ strength and natural water content were similar to those of hard clays. They concluded that particle distribution has a relatively significant impact on the in situ strength of natural deposits.

Soil distribution exhibits typical regional characteristics. To date, relatively few studies have been conducted to examine the creep behavior of IMT deposits. In this study, the creep behavior of Dalian IMT clays was examined by onedimensional (1D) and drained triaxial creep tests. Based on the creep test results, a creep equation that considers the primary and secondary consolidation of deposits and an improved Mesri creep equation were established, providing a reference for predicting foundation deformation and settlement.

\section{Materials and Methods}

2.1. Soil Samples. Test samples were collected from an undisturbed seabed at a depth of 5-30 $\mathrm{m}$ at a construction site. These samples were gray-grayish brown IMT and silty clays. Table 1 summarizes their physical property indices. As shown in Table 1, the marine deposits (mud and muddy clays) had relatively high water contents and void ratios and relatively small unit weights and were in a liquid-plastic state. In contrast, the IMT deposits (clays and silty clays) had relatively low water contents and void ratios and relatively large unit weights and were in a plastic state.

2.2. Test Methods. The soil samples collected at depths of $14 \mathrm{~m}$ (clay), $18 \mathrm{~m}$ (clay), and $25 \mathrm{~m}$ (silty clay) were subjected to a 1D creep test under drained conditions on a consolidometer (WG-1B). Repeated tests were performed for each group of samples. Each sample had a diameter of $61.8 \mathrm{~mm}$ and a height of $20 \mathrm{~mm}$. Considering the in situ stress of the soil and the overlying backfill load, the following test load levels were applied: 50, 100, 200, 400, 800, and $1,600 \mathrm{kPa}$. After each load application, the amount of deformation was read at preset intervals until the deformation below $0.01 \mathrm{~mm}$ within $24 \mathrm{~h}$. The temperature was controlled at $20 \pm 1{ }^{\circ} \mathrm{C}$ during the test process.

Drained triaxial creep tests were performed on a soil triaxial rheometer (CSS-2901TS). Each sample had a diameter of $39.1 \mathrm{~mm}$ and a height of $80 \mathrm{~mm}$. A multistage (either four or five stages) loading procedure was adopted. Four levels of cell pressure were used in the tests, namely, $100,200,400$, and $800 \mathrm{kPa}$. When the soil sample is failed in shear in the consolidated-drained shear test under the same cell pressure, the deviatoric stress $\left(q_{\mathrm{f}}\right)$ was recorded and used
TABLE 1: Physical properties indices of clays.

\begin{tabular}{lccccccc}
\hline Genetic factor & Soil & $\begin{array}{c}W \\
(\%)\end{array}$ & $\begin{array}{c}\gamma \\
\left(\mathrm{kN} / \mathrm{m}^{3}\right)\end{array}$ & $e$ & $\begin{array}{c}w_{\mathrm{L}} \\
(\%)\end{array}$ & $I_{\mathrm{P}}$ & $I_{\mathrm{L}}$ \\
\hline Marine deposit & $\begin{array}{c}\text { Mud } \\
\text { Muddy } \\
\text { clay }\end{array}$ & 63.7 & 16.0 & 1.75 & 48.5 & 24.3 & 1.63 \\
$\begin{array}{l}\text { Marine- } \\
\text { terrestrial } \\
\text { deposit }\end{array}$ & $\begin{array}{c}\text { Clay } \\
\text { Silty }\end{array}$ & 39.2 & 17.2 & 1.30 & 40.2 & 19.9 & 1.38 \\
\hline
\end{tabular}

to determine the load increment $\left(q_{\mathrm{f}} / 4-q_{\mathrm{f}} / 5\right)$ for each soil sample at each stage. Sample disturbance was minimized during the tests. All samples were saturated by standard increments of cell pressure and back pressure. The pore water pressure coefficient $B$-value was measured to confirm saturation until it reached 0.98. Each sample was successively saturated, consolidated, and subjected to multistage loading. Deformation below 0.01 within $24 \mathrm{~h}$ was set as the standard. The temperature was controlled at $20 \pm 1^{\circ} \mathrm{C}$ during the test process.

\section{Test Results and Analysis from One- Dimensional Creep Test}

3.1. Creep Behavior. Figure 1 shows the time-history curves of strain and void ratio of the soil samples collected at depths of $14 \mathrm{~m}, 18 \mathrm{~m}$, and $25 \mathrm{~m}$. As shown in Figure 1, the soil strain was relatively small during the initial loading stage but gradually increased and eventually changed slowly as the consolidation time increased. The soil sample deformation was relatively large under high levels of vertical pressure (400 and $800 \mathrm{kPa}$ ). The longer the settling time, the more pronounced the boundary between primary and secondary consolidation. According to the laboratory experiments, the in situ void ratio $e_{0}$, in situ effective stress $\sigma_{\mathrm{v} 0}^{\prime}$, preconsolidation pressure $\sigma_{\mathrm{p}}^{\prime}$, and overconsolidation ratio (OCR) at depths of $14 \mathrm{~m}, 18 \mathrm{~m}$, and $25 \mathrm{~m}$ are listed in Table 2. It can be concluded that the clays at depths of $14 \mathrm{~m}, 18 \mathrm{~m}$, and $25 \mathrm{~m}$ belong to slightly overconsolidated soil. For a normal consolidated or slightly overconsolidated soil, when the load level was lower than the preconsolidation pressure, its deformation was relatively small; when the load level was higher than the preconsolidation pressure, its deformation and its rate of deformation increased, resulting in the aforementioned creep behavior. Contrary to the pattern of change in the strain, the void ratio decreased as the consolidation time increased. The slopes of the curves changed relatively significantly during the initial loading stage and remained basically unchanged during the later loading stage. The void ratio-time curves under low levels of consolidation pressure (100 and $200 \mathrm{kPa}$ ) were nearly straight lines, whereas those under high levels of consolidation pressure exhibited an inverse "S" shape. This is similar to the pattern of deformation of Hong Kong deposits reported by Yin [8]. Overall, the patterns of deformation of the soil samples collected at various depths $(14,18$, and $25 \mathrm{~m})$ were basically consistent. The results obtained using the log time method show that primary consolidation was basically completed 

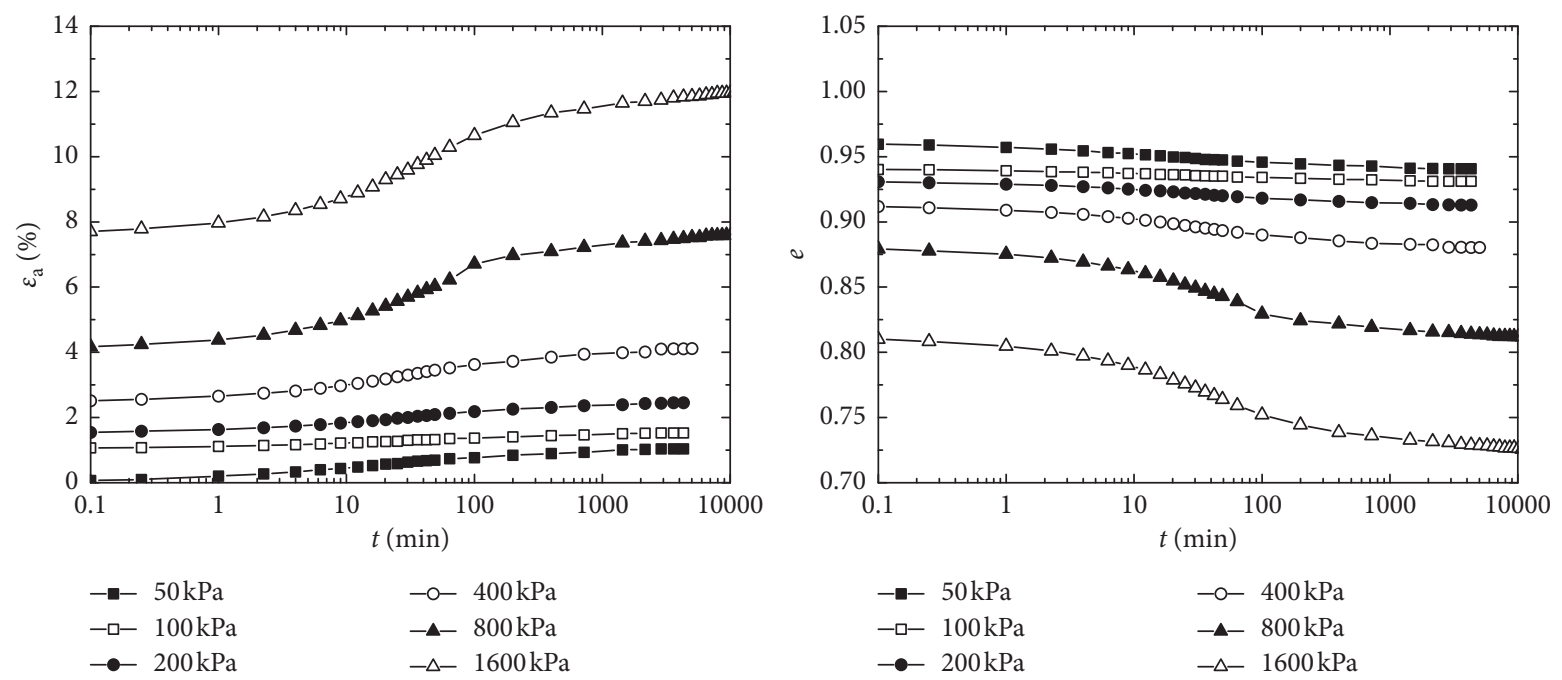

(a)
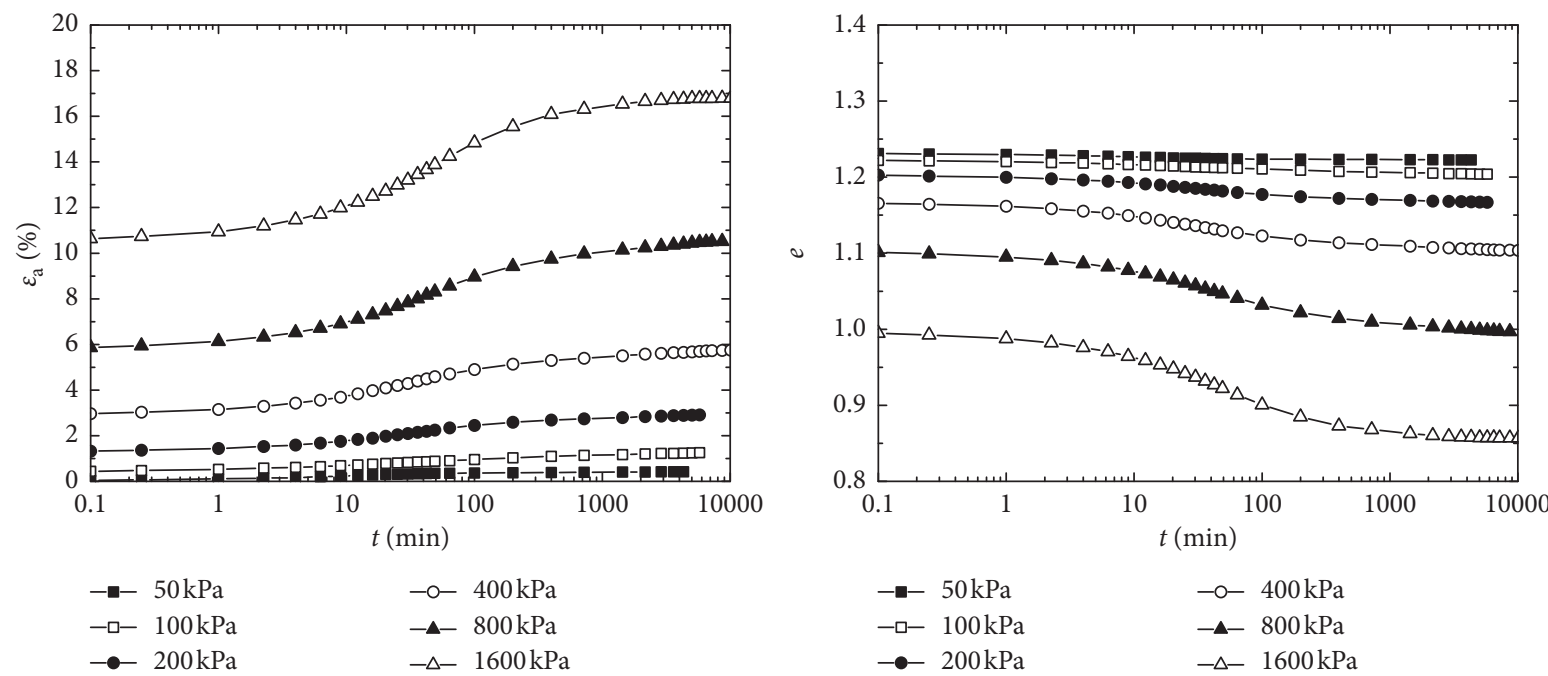

(b)
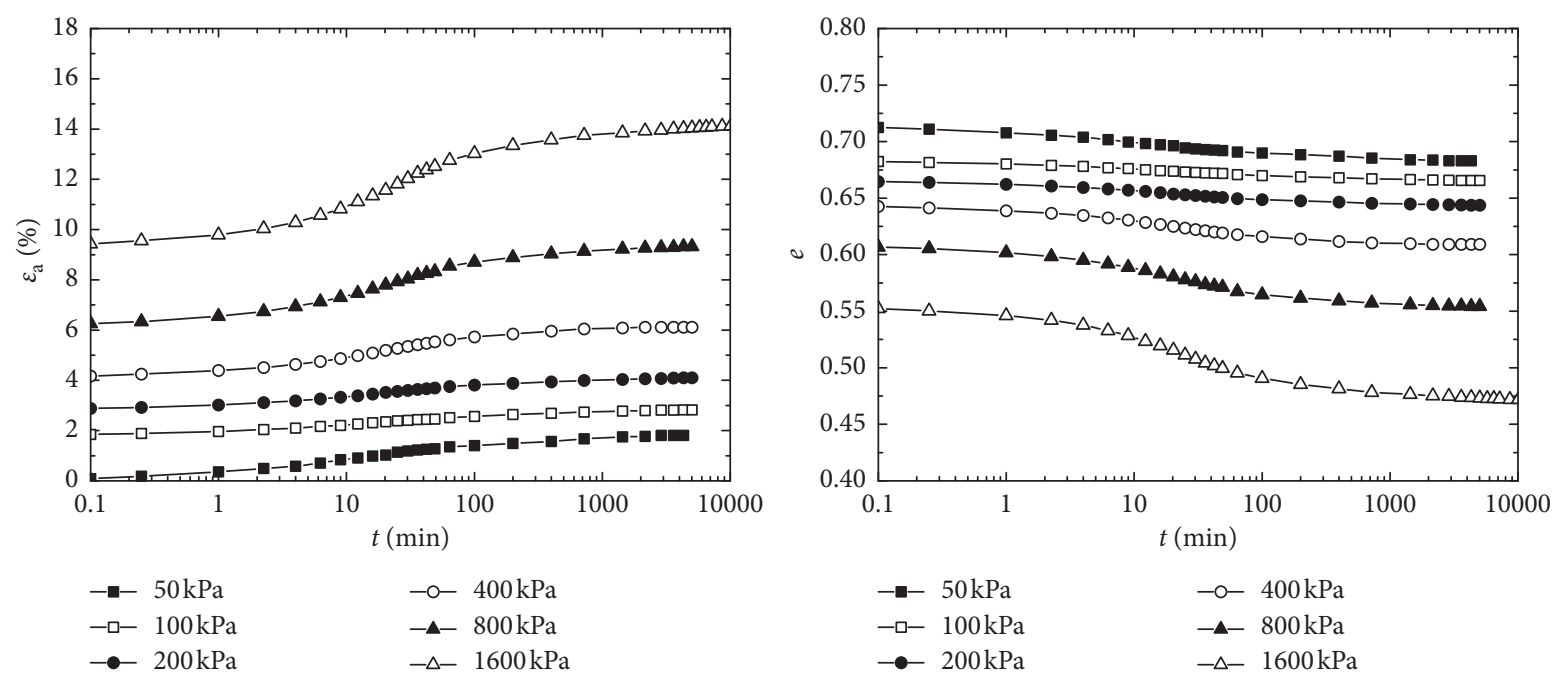

(c)

Figure 1: $\varepsilon_{\mathrm{a}}$ or $e$ versus $t$ at different depths. (a) $14 \mathrm{~m}$, (b) $18 \mathrm{~m}$, and (c) $25 \mathrm{~m}$. 
TABLE 2: Consolidation state of clays at different depths.

\begin{tabular}{lcccc}
\hline Depth $(\mathrm{m})$ & $e_{0}$ & $\sigma_{\mathrm{v} 0}^{\prime}(\mathrm{kPa})$ & $\sigma_{\mathrm{p}}^{\prime}(\mathrm{kPa})$ & OCR \\
\hline 14 & 1.12 & 100 & 195 & 1.95 \\
18 & 1.10 & 135 & 210 & 1.56 \\
25 & 0.71 & 200 & 220 & 1.10 \\
\hline
\end{tabular}

within 100 min after each level of consolidation pressure was applied.

To analyze the pattern of change in the strain with consolidation pressure, the creep test results for the soil samples collected at a depth of $25 \mathrm{~m}$ are used as an example. Figure 2 shows their isochronous stress-strain curves which depict notable nonlinear characteristics at different times. As the consolidation pressure increased, the slopes of the curves were more sharply increased. When the consolidation pressure remained constant, the strain increased with time. When the strain remained constant, the consolidation pressure decreased with time. Thus, the Dalian IMT deposits displayed typical nonlinear creep behavior which was related to the loading time. Under low consolidation pressures (50 and $100 \mathrm{kPa}$ ), the slopes of the isochronous curves were relatively small; under high consolidation pressures (800 and $1,600 \mathrm{kPa}$ ), the slopes of the isochronous curves were relatively large.

3.2. Secondary Consolidation Coefficient. Buisman noted that the secondary consolidation coefficient for the secondary consolidation and deformation stage could be calculated using the following equation:

$$
C_{\alpha}=\frac{e_{1}-e_{2}}{\lg t_{2}-\lg t_{1}}
$$

where $C_{\alpha}$ is the secondary consolidation coefficient, $t_{1}$ is the time at which $100 \%$ primary consolidation is achieved, $t_{2}$ is the calculated time for secondary consolidation, and $e_{1}$ and $e_{2}$ are the void ratios corresponding to $t_{1}$ and $t_{2}$, respectively.

Figure 3 shows the curves of changes in the secondary consolidation coefficient of the soil samples collected at various depths $(14,18$, and $25 \mathrm{~m})$ with time $\left(t_{1}=100 \mathrm{~min}\right)$, which were used to analyze the pattern of changes in the secondary consolidation coefficient with time. As shown in Figure 3, during the secondary consolidation and deformation stage, the secondary consolidation coefficient gradually decreased as time increased. Under low consolidation pressures, the slopes of the curves were relatively small, and the curves were nearly straight lines. As the consolidation pressure increased, the slopes of the curves gradually increased and the corresponding secondary consolidation coefficients also increased significantly. Overall, the soil samples collected at a depth of $18 \mathrm{~m}$ had a relatively large secondary consolidation coefficient, whereas the soil samples collected at a depth of $25 \mathrm{~m}$ had a relatively small secondary consolidation coefficient. Based on the classification of the secondary compression coefficient in Reference [9], the deposits at a depth of $18 \mathrm{~m}$ are soils with high secondary compressibility and those at depths of 14 and $25 \mathrm{~m}$ are soils with medium secondary compressibility. Thus,

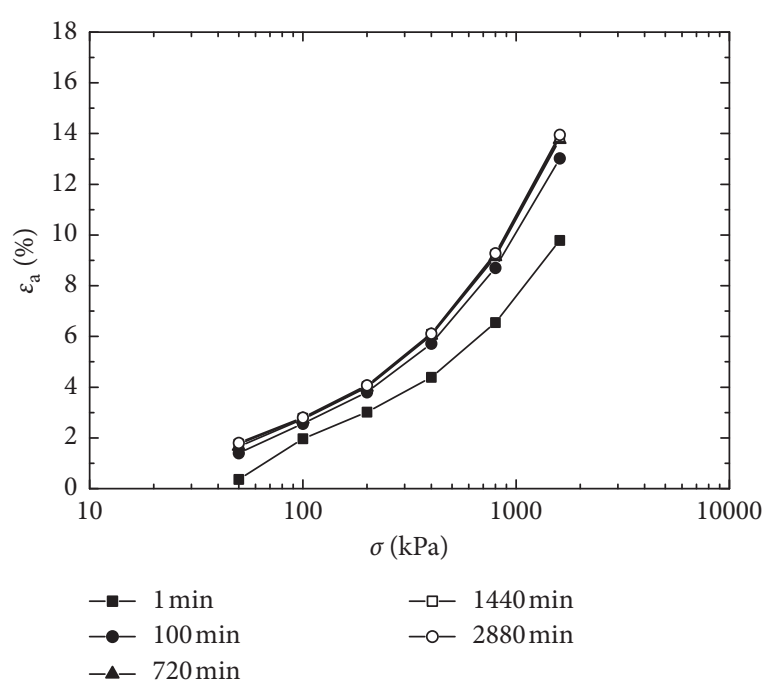

FIGURE 2: Isochronous curve of $\varepsilon_{\mathrm{a}}$ versus $\sigma$ of silty clay at $25 \mathrm{~m}$ depth.

the Dalian IMT deposits are soils with medium to high secondary compressibility.

3.3. Relationships between Secondary Consolidation Coefficient and Compression Index. Mesri and Godlewski [10] found that the ratio of the secondary consolidation coefficient to the compression index is in the range of 0.01 to 0.07 for undisturbed soils and is a constant for the same type of undisturbed soil. This conclusion has been accepted by a number of researchers [11-15]. Through calculation, it was found that the ratios of the secondary consolidation coefficient to the compression index for the Dalian IMT deposit samples collected from depths of 14,18 , and $25 \mathrm{~m}$ ranged from $0.033-0.058$, consistent with Mesri's conclusion.

\section{One-Dimensional Creep Equations}

4.1. Deriving the Creep Equations. The creep test results for the silty clay samples collected at a depth of $25 \mathrm{~m}$ are used as an example. Figure 4 shows the log-log plots of strain versus time based on the test results. Table 3 summarizes the fitted equations. As shown in Figure 4, there was a nearly linear strain-time relationship under each level of consolidation pressure, which satisfied the following relationship:

$$
\lg \varepsilon(\sigma, t)-\lg \varepsilon\left(\sigma, t_{0}\right)=m\left(\lg t-\lg t_{0}\right) .
$$

By rearranging equation (2), we have the following equation:

$$
\varepsilon(\sigma, t)=\varepsilon\left(\sigma, t_{0}\right)\left(\frac{t}{t_{0}}\right)^{m},
$$

where $\sigma$ is the consolidation stress, $t$ is the consolidation time, $t_{0}$ is the reference time, $m$ is the slope of the log strain versus log time, and $\varepsilon(\sigma, t)$ is the strain corresponding to $\sigma$ and $t$.

Figure 5 shows the isochronous log-log plots of strain versus consolidation pressure for the silty clay samples collected at a depth of $25 \mathrm{~m}$, showing that the strain 


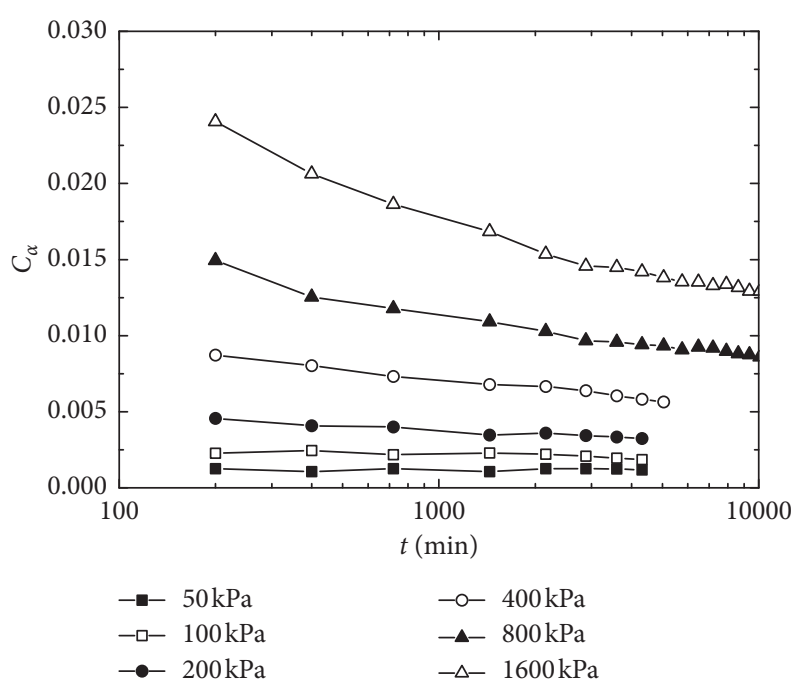

(a)

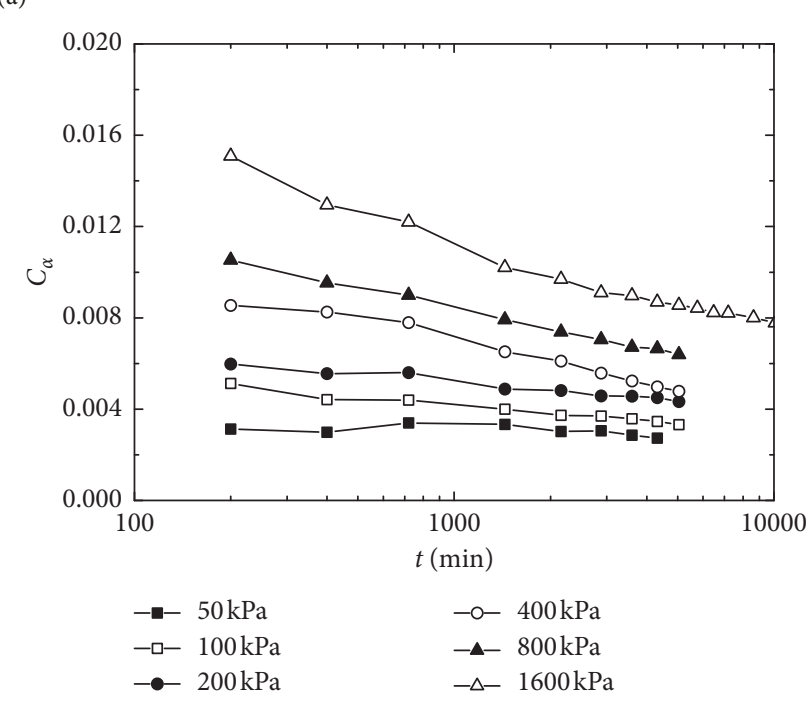

(c)

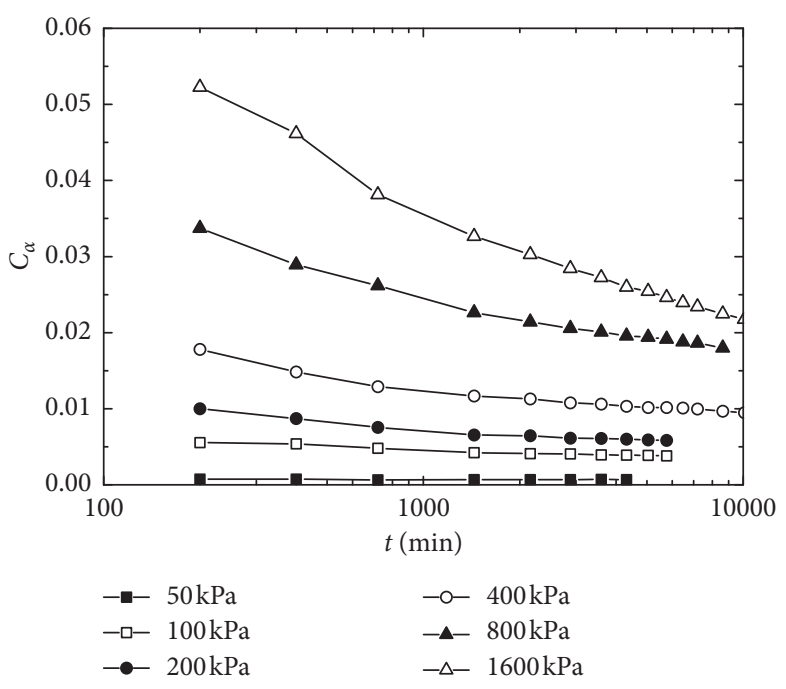

(b)

Figure 3: $C_{\alpha}$ versus $t$ at different depths. (a) $14 \mathrm{~m}$, (b) $18 \mathrm{~m}$, and (c) $25 \mathrm{~m}$.

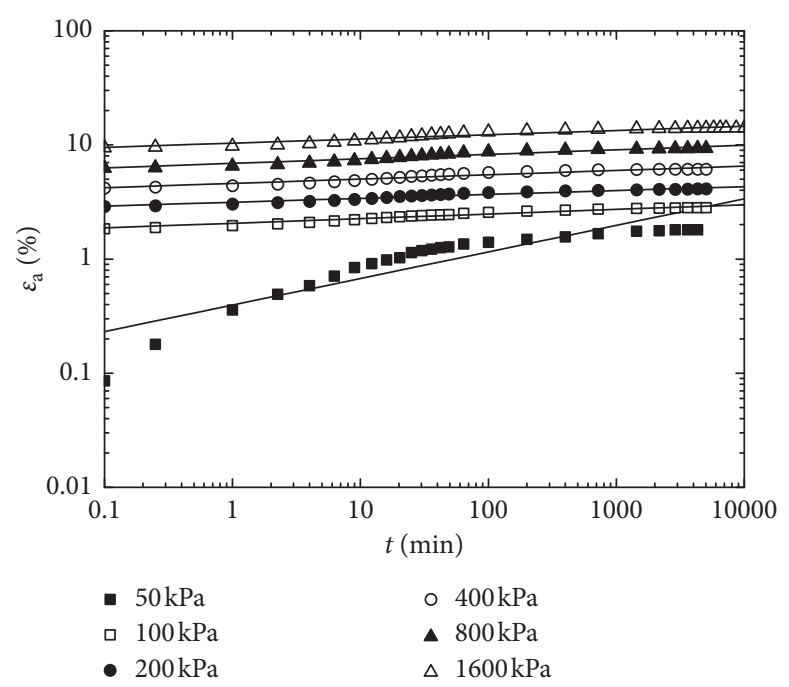

Figure 4: Double logarithmic curves of $\varepsilon_{\mathrm{a}}$ versus $t$. 
TABLE 3: Fitting equation between stress and time.

\begin{tabular}{lcc}
\hline Pressure $(\mathrm{kPa})$ & Equation & $R$ \\
\hline 50 & $\lg (\varepsilon)=0.11268 \lg (t)-0.48949$ & 0.89886 \\
100 & $\lg (\varepsilon)=0.07091 \lg (t)+0.37196$ & 0.98067 \\
200 & $\lg (\varepsilon)=0.05368 \lg (t)+0.53082$ & 0.97618 \\
400 & $\lg (\varepsilon)=0.04435 \lg (t)+0.74367$ & 0.96874 \\
800 & $\lg (\varepsilon)=0.03996 \lg (t)+0.88527$ & 0.96786 \\
1600 & $\lg (\varepsilon)=0.03124 \lg (t)+1.02855$ & 0.96529 \\
\hline
\end{tabular}

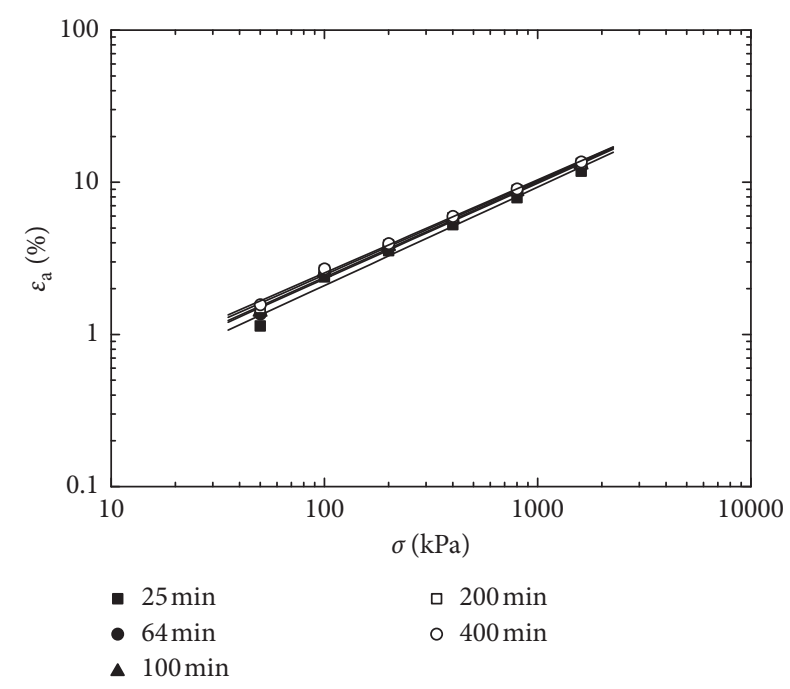

FIGURE 5: Double logarithmic curves of $\varepsilon_{\mathrm{a}}$ versus $\sigma$.

increased as the consolidation pressure increased, with a nearly linear strain-consolidation pressure relationship at various times. The average slope of the isochronous curves was 0.63338 . The strain and the consolidation stress satisfied the following relationship:

$$
\lg \varepsilon(\sigma, t)-\lg \varepsilon\left(\sigma_{0}, t\right)=n\left(\lg \sigma-\lg \sigma_{0}\right) .
$$

By rearranging equation (4), we have the following equation:

$$
\varepsilon(\sigma, t)=\varepsilon\left(\sigma_{0}, t\right)\left(\frac{\sigma}{\sigma_{0}}\right)^{n},
$$

where $\sigma_{0}$ is the reference stress and $n$ is the slope of the strain-consolidation stress curve.

By combining equations (3) and (5), the following creep equation is obtained:

$$
\varepsilon(\sigma, t)=\varepsilon\left(\sigma_{0}, t_{0}\right)\left(\frac{t}{t_{0}}\right)^{m}\left(\frac{\sigma}{\sigma_{0}}\right)^{n},
$$

where $\varepsilon\left(\sigma_{0}, t_{0}\right)$ is the strain corresponding to the reference stress $\sigma_{0}$ and the reference time $t_{0}$ and $m$ is the slope of the $\log$ strain versus log time.

Based on the previously mentioned analysis, the creep equation contains three parameters, namely, $\varepsilon\left(\sigma_{0}, t_{0}\right), m$, and $n$. Of these, $\varepsilon\left(\sigma_{0}, t_{0}\right)$ is the strain corresponding to the reference time $t_{0}$ and the reference stress $\sigma_{0}, m$ is the slope of the log strain versus log time, and $n$ is the slope of the strainstress curve. All three parameters can be determined based on the creep test results. Table 4 summarizes the model parameters for various levels of consolidation stress obtained by creep test results regression analysis for the soil samples collected at depths of 14,18 , and $25 \mathrm{~m}$.

4.2. Verifying the Creep Equations. To examine the equation's reliability, calculations were performed using the creep equation based on the creep test results for soil samples collected at depths of 14, 18, and $25 \mathrm{~m}$. Figure 6 shows the results which indicate a relatively large difference between the test and calculated values for the initial stage of consolidation pressure. As the consolidation time increased, the consistency between the test and calculated values gradually increased. Overall, there was a high degree of consistency between the calculated and test results. This suggests that this model is suitable for describing the creep properties of the Dalian IMT deposits. In addition, the creep equation features only a few yet highly accessible parameters and can be used to provide a reference for predicting long-term foundation deformation.

\section{Test Results and Analysis from Drained Triaxial Creep Test}

5.1. Axial Strain and Creep Time. To analyze the drained creep properties of the IMT clays, the test data were processed using Chen's loading method according to Reference [16]. Figure 7 shows the creep curves of the silty clay collected at depths of $26 \mathrm{~m}$ under cell pressures of 100,200,400, and $800 \mathrm{kPa}$. The creep curves exhibited notable nonlinear characteristics. During the initial stage of the deviatoric stress, the axial strain changed relatively significantly. As time increased, the strain slowly changed. The soil displayed notable attenuation creep behavior under the action of a low deviatoric stress and pronounced acceleration creep behavior under the action of the failure deviatoric stress. Overall, the failure deviatoric stress increased as the cell pressure increased. The patterns of soil deformation under the action of various cell pressures and deviatoric stresses remained basically consistent. The soil deformation basically changed slowly within 5,000 min under the action of the deviatoric stress. Based on the previously mentioned analysis, the Dalian IMT clays exhibited typical nonlinear creep behavior. The axial strains increased as the deviatoric stress increased and slowly changed with time. In addition, the IMT clays displayed attenuation and acceleration creep behavior during the entire creep process.

5.2. Volumetric Strain and Creep Time. Figure 8 shows the volumetric strain versus time curves under cell pressures of $100,200,400$, and $800 \mathrm{kPa}$. The volumetric strain gradually decreased as the creep time and deviatoric stress increased (except the action of the failure deviatoric stress), suggesting that the soil showed shear contraction behavior. Under the action of the failure deviatoric stress, the volumetric strain first decreased and then increased, suggesting that the soil displayed shear contraction and shear dilation behavior, which differs from the pattern of changes in the volumetric 
TABLE 4: Fitting model parameters of clays at different depths.

\begin{tabular}{|c|c|c|c|c|c|c|}
\hline Depth (m) & Pressure $(\mathrm{kPa})$ & Reference pressure $(\mathrm{kPa})$ & Reference time (min) & $\varepsilon\left(\sigma_{0}, t_{0}\right)(\%)$ & $m$ & $n$ \\
\hline \multirow{6}{*}{14} & 50 & 100 & 100 & 1.370 & 0.12573 & 0.75518 \\
\hline & 100 & 100 & 100 & 1.370 & 0.03569 & 0.75518 \\
\hline & 200 & 100 & 100 & 1.370 & 0.03242 & 0.75518 \\
\hline & 400 & 100 & 100 & 1.370 & 0.02535 & 0.75518 \\
\hline & 800 & 100 & 100 & 1.370 & 0.03024 & 0.75518 \\
\hline & 1600 & 100 & 100 & 1.370 & 0.02057 & 0.75518 \\
\hline \multirow{6}{*}{18} & 50 & 100 & 100 & 0.955 & 0.11295 & 1.06804 \\
\hline & 100 & 100 & 100 & 0.955 & 0.09645 & 1.06804 \\
\hline & 200 & 100 & 100 & 0.955 & 0.08710 & 1.06804 \\
\hline & 400 & 100 & 100 & 0.955 & 0.07130 & 1.06804 \\
\hline & 800 & 100 & 100 & 0.955 & 0.04549 & 1.06804 \\
\hline & 1600 & 100 & 100 & 0.955 & 0.02077 & 1.06804 \\
\hline \multirow{6}{*}{25} & 50 & 100 & 100 & 2.145 & 0.11268 & 0.63338 \\
\hline & 100 & 100 & 100 & 2.145 & 0.07091 & 0.63338 \\
\hline & 200 & 100 & 100 & 2.145 & 0.05368 & 0.63338 \\
\hline & 400 & 100 & 100 & 2.145 & 0.04435 & 0.63338 \\
\hline & 800 & 100 & 100 & 2.145 & 0.03996 & 0.63338 \\
\hline & 1600 & 100 & 100 & 2.145 & 0.03124 & 0.63338 \\
\hline
\end{tabular}

deformation of the Tianjin Binhai soft clays [17], which exhibit only shear contraction behavior.

5.3. Deviatoric Stress and Axial Strain. To analyze the stressstrain relationship of the clay samples, the creep test results obtained under a cell pressure of $100 \mathrm{kPa}$ for the silty clay collected at a depth of $26 \mathrm{~m}$ are used as an example. Figure 9 shows their deviatoric stress-strain isochronous curves which highlighting a notable nonlinear stress-strain relationship. As the deviatoric stress increased, the axial strain gradually increased. Under the action of a low deviatoric stress, the slopes of the isochronous curves were relatively small. As the deviatoric stress increased, the slopes of the curves gradually increased, and the corresponding axial strain also increased. Similar to the creep behavior of soft clays reported by Liu et al. [18], the isochronous curves at various times exhibited a basically consistent distribution. When the deviatoric stress remained constant, the axial strain increased with time. Based on the aforementioned analysis, the Dalian IMT clays exhibited typical nonlinear creep behavior, which became increasingly pronounced as the deviatoric stress increased.

5.4. Axial Strain Rates and Creep Time. Figure 10 shows the curves of changes in the strain rate of the silty clay collected at a depth of $26 \mathrm{~m}$ with time. It illustrated that the strain rate decreased with time on the log-log plots. Under the action of the deviatoric stress, the slopes of the curves were relatively small during the initial stage (within $100 \mathrm{~min}$ ). After the creep time exceeded $100 \mathrm{~min}$, the slopes of the curves remained basically constant. This is similar to the creep behavior of soft clays reported by Lai et al. [19] and Wang and Yin [20]. In addition, the strain rate of the soil increased as the deviatoric stress increased. During the later stage of loading (after $100 \mathrm{~min}$ ), the slopes of the curves under the action of various levels of deviatoric stress (except for the failure deviatoric stress) were basically the same and the $m$ - value (slope) ranged from 0.77 to 0.82 , suggesting that the deviatoric stress had a relatively insignificant impact on the $m$-value. In terms of the creep process, under the action of a low deviatoric stress $(35,75$, and $120 \mathrm{kPa})$, the creep rate of the soil decreased with time, and the soil displayed attenuation creep behavior. Under the action of the failure deviatoric stress, the creep rate of the soil first decreased and then increased and the soil displayed attenuation and acceleration creep behavior. This corroborates the conclusion derived from the previous analysis.

5.5. Axial Strain Rates and Deviatoric Stress. Figure 11 shows the axial strain rate versus deviatoric stress isochronous curves. The creep behavior of the Dalian IMT clays was similar to that of soft clays reported by Yan et al. [21]. As the deviatoric stress increased, the axial strain rate gradually increased. As the creep time increased, the axial strain rate gradually decreased. Under the action of a low deviatoric stress, the slopes of the curves were relatively small. As the deviatoric stress increased, the slopes of the curves increased, suggesting that the strain rate increased as the deviatoric stress increased. When the deviatoric stress remained constant, the strain rate decreased with creep time. When the strain rate remained constant, the deviatoric stress increased with creep time. Thus, for the Dalian IMT clays, there was a nonlinear relationship between axial strain rate and deviatoric stress, which became increasingly insignificant as creep time increased.

\section{Improved Mesri Creep Equations}

6.1. Mesri Creep Equation. There are a relatively large number of empirical models for the creep behavior of clays, represented by the Singh-Mitchell and Mesri models [2229]. The Singh-Mitchell model is only suitable for describing the stress-strain-time relationship within $20-80 \%$ of the deviatoric stress level. Therefore, the Mesri model is more advantageous. In this study, an attempt is made to use the 

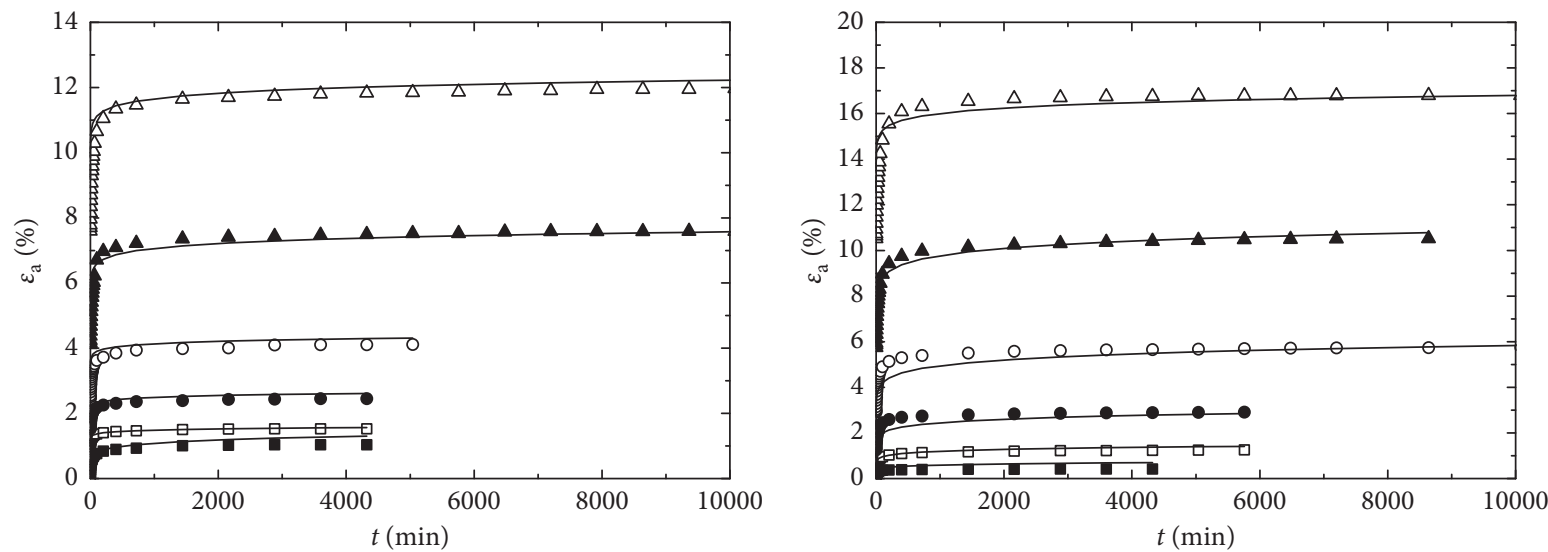
$\Delta 1600 \mathrm{kPa}$ test value
- $800 \mathrm{kPa}$ test value
- $400 \mathrm{kPa}$ test value
․ $100 \mathrm{kPa}$ test value
- $50 \mathrm{kPa}$ test value
_ Calculated value

- $200 \mathrm{kPa}$ test value

(a)

$\triangle 1600 \mathrm{kPa}$ test value

- $800 \mathrm{kPa}$ test value

- $400 \mathrm{kPa}$ test value $200 \mathrm{kPa}$ test value $\quad 100 \mathrm{kPa}$ test value

- $50 \mathrm{kPa}$ test value

_ Calculated value

(b)

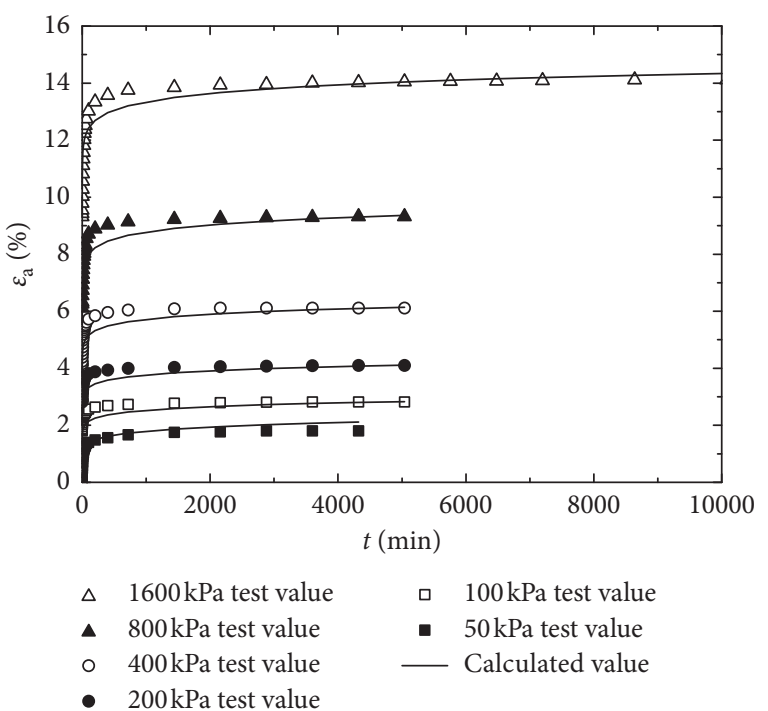

(c)

FIgURE 6: Test results compared with calculation results at different depths. (a) $14 \mathrm{~m}$, (b) $18 \mathrm{~m}$, and (c) $25 \mathrm{~m}$.

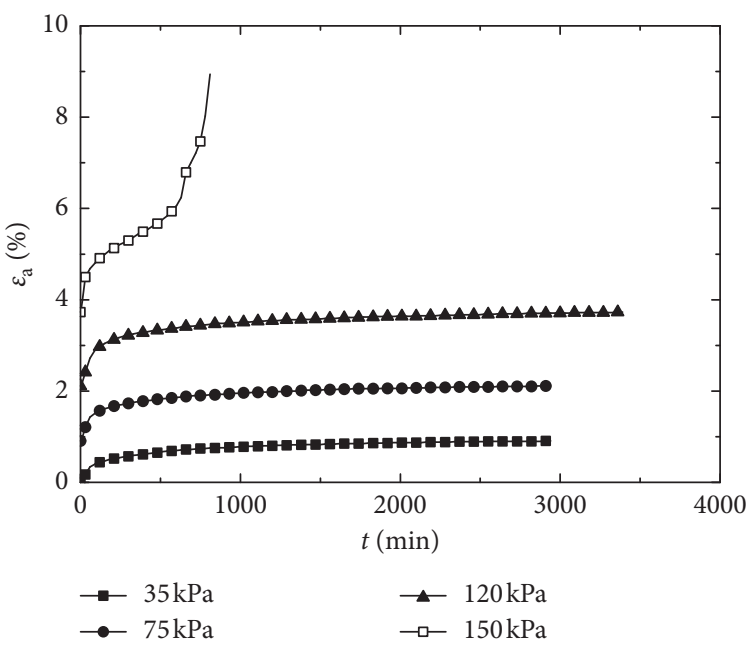

(a)

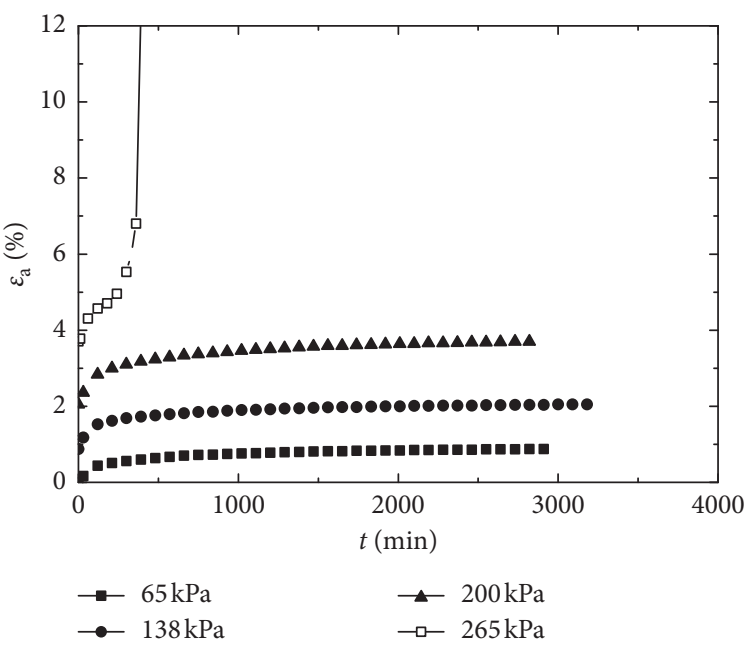

(b)

Figure 7: Continued. 


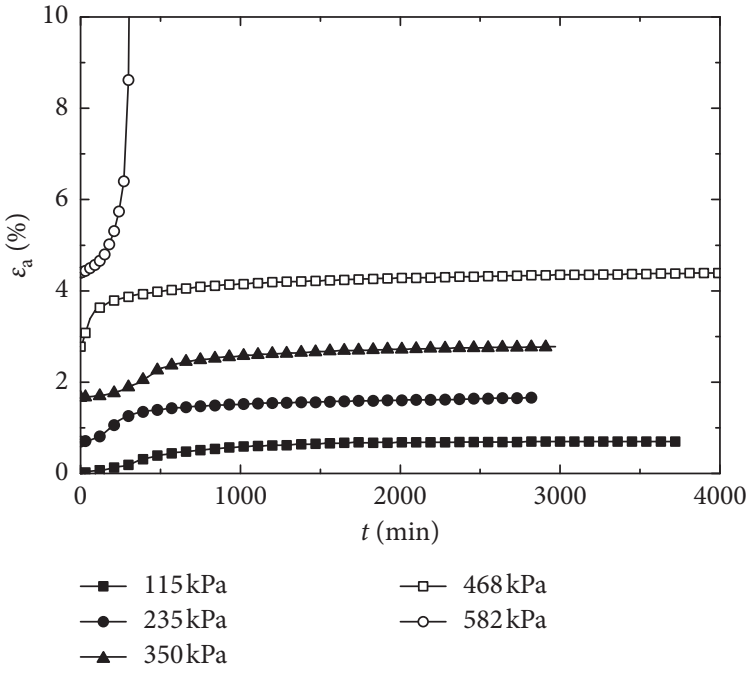

(c)

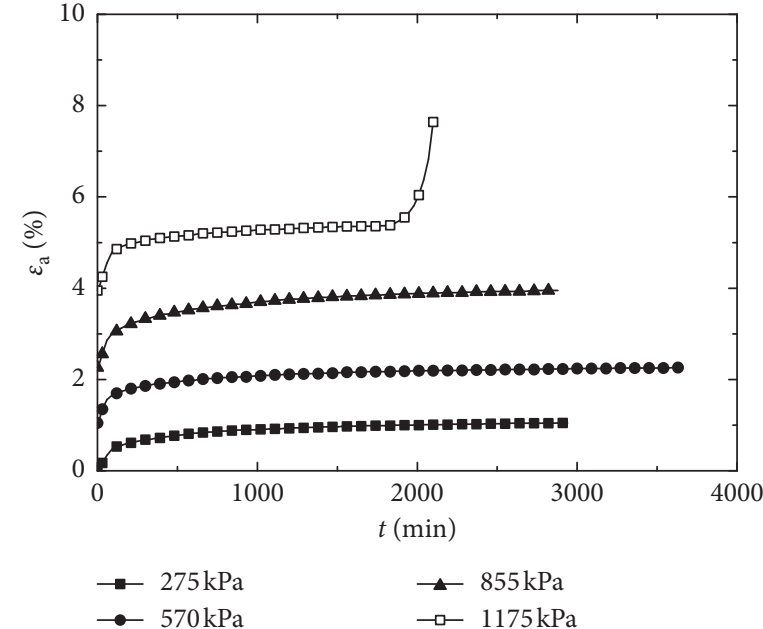

(d)

Figure 7: $\varepsilon_{\mathrm{a}}$ versus $t$ under different cell pressures. (a) $100 \mathrm{kPa}$, (b) $200 \mathrm{kPa}$, (c) $400 \mathrm{kPa}$, and (d) $800 \mathrm{kPa}$.

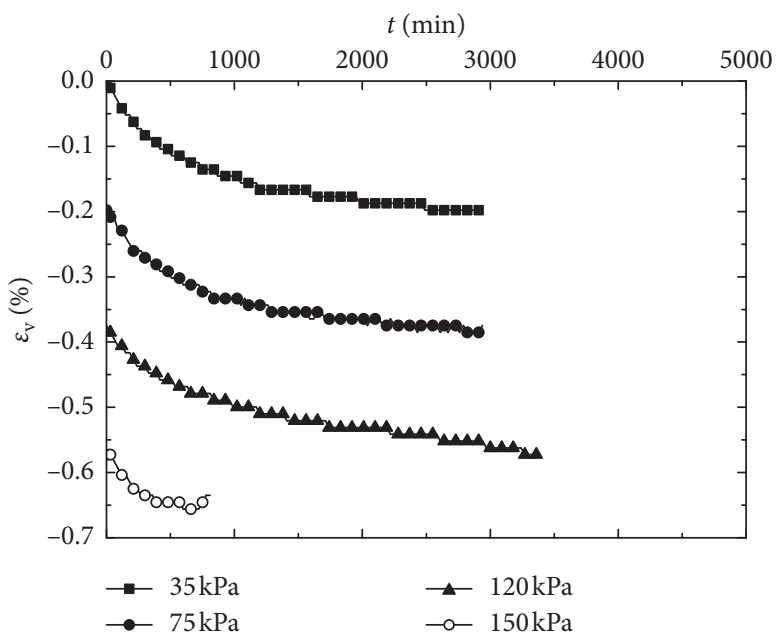

(a)

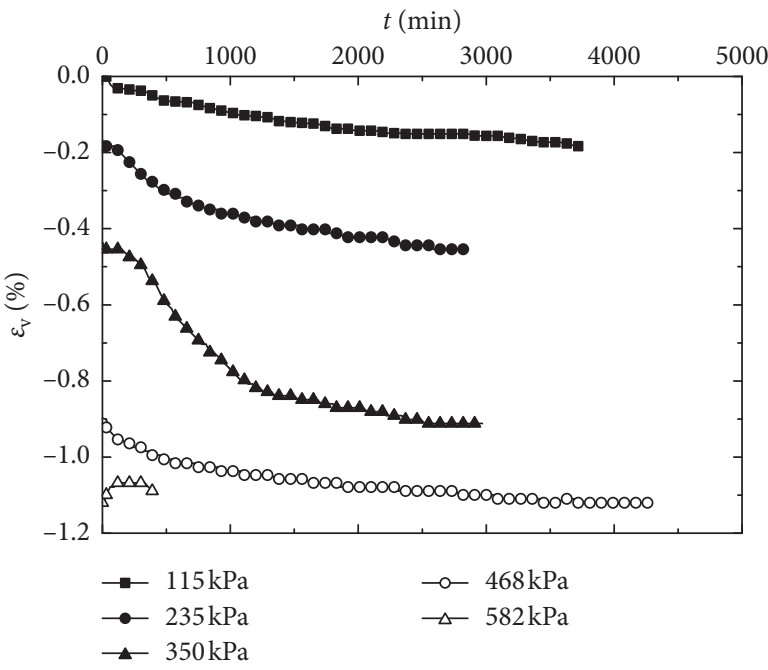

(c)

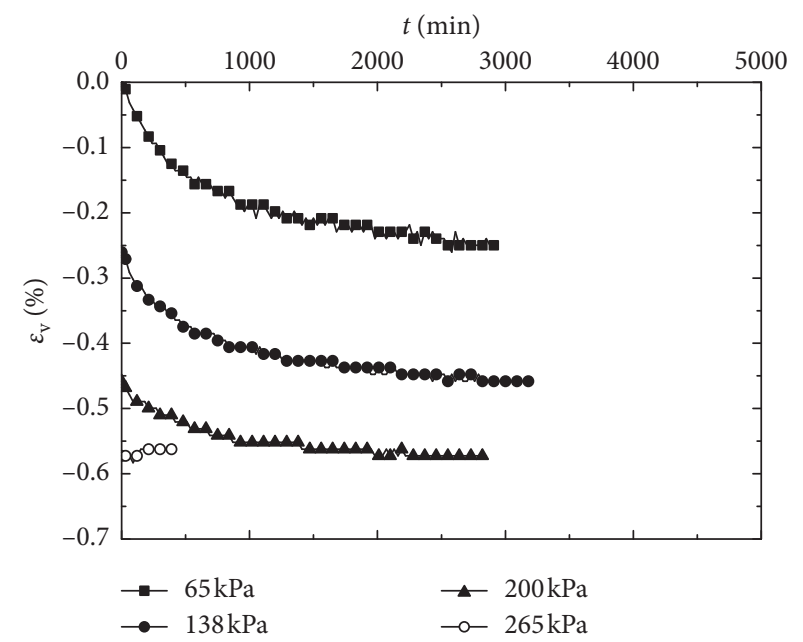

(b)

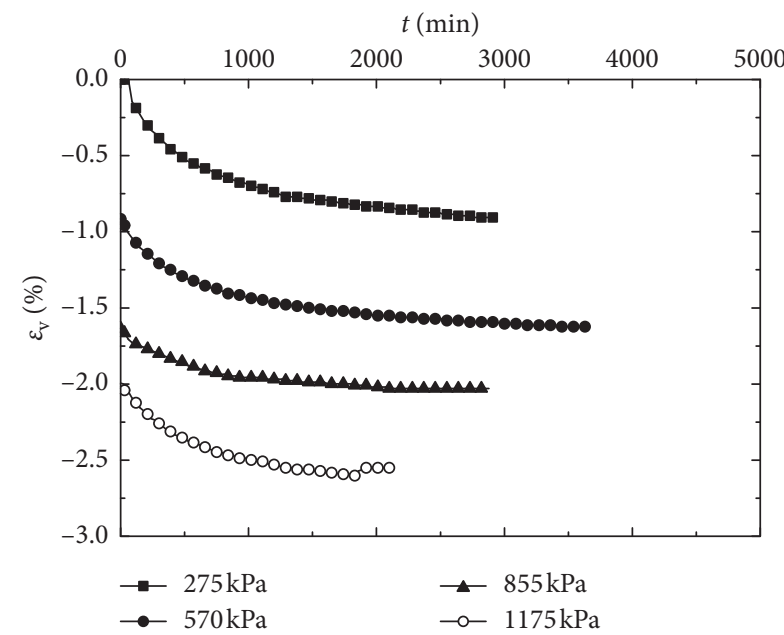

(d)

Figure 8: $\varepsilon_{\mathrm{v}}$ versus $t$ under different cell pressures. (a) $100 \mathrm{kPa}$, (b) $200 \mathrm{kPa}$, (c) $400 \mathrm{kPa}$, and (d) $800 \mathrm{kPa}$. 


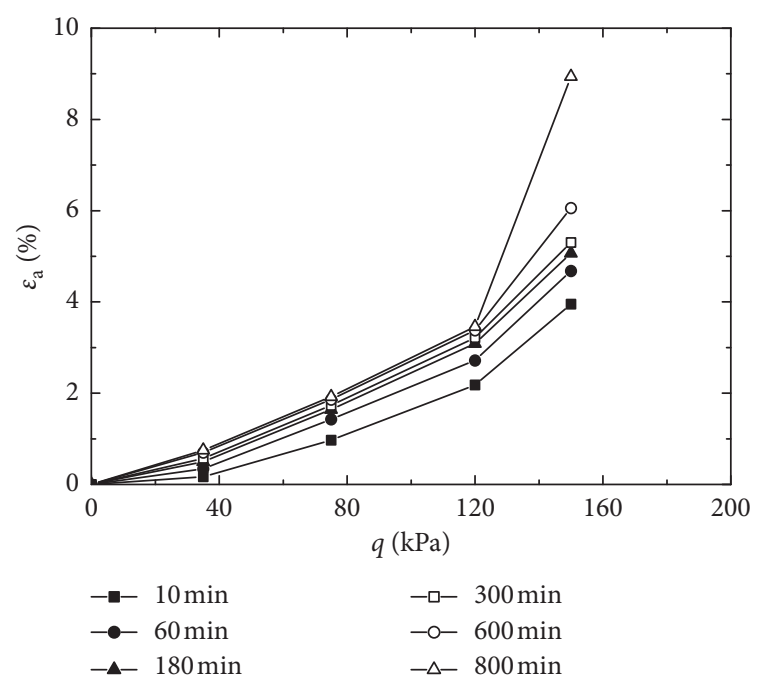

FIGURE 9: Isochronal curves of $\varepsilon_{\mathrm{a}}$ versus $q$ under $100 \mathrm{kPa}$ cell pressure.

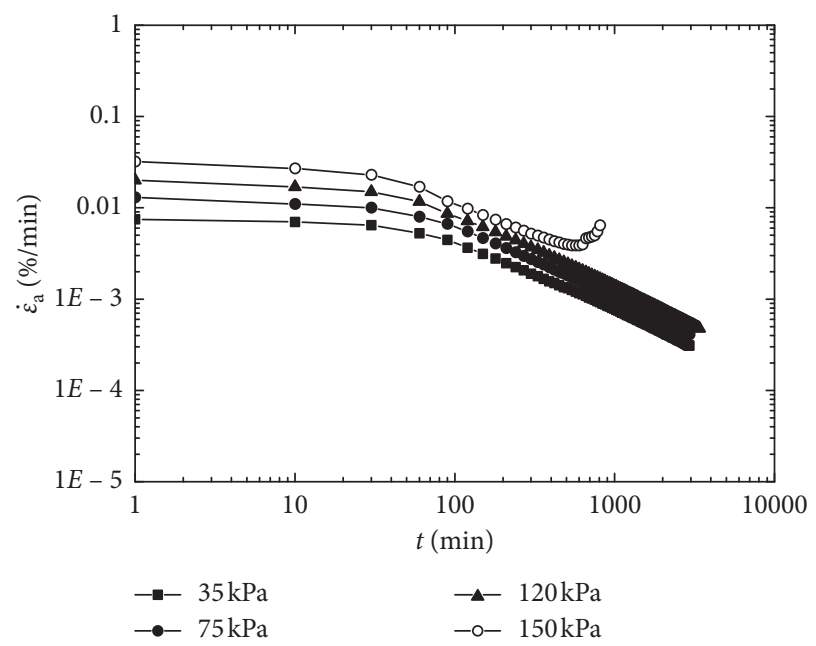

Figure 10: Double logarithmic curves of $\dot{\varepsilon}_{\text {a }}$ versus $t$ under $100 \mathrm{kPa}$ cell pressure.

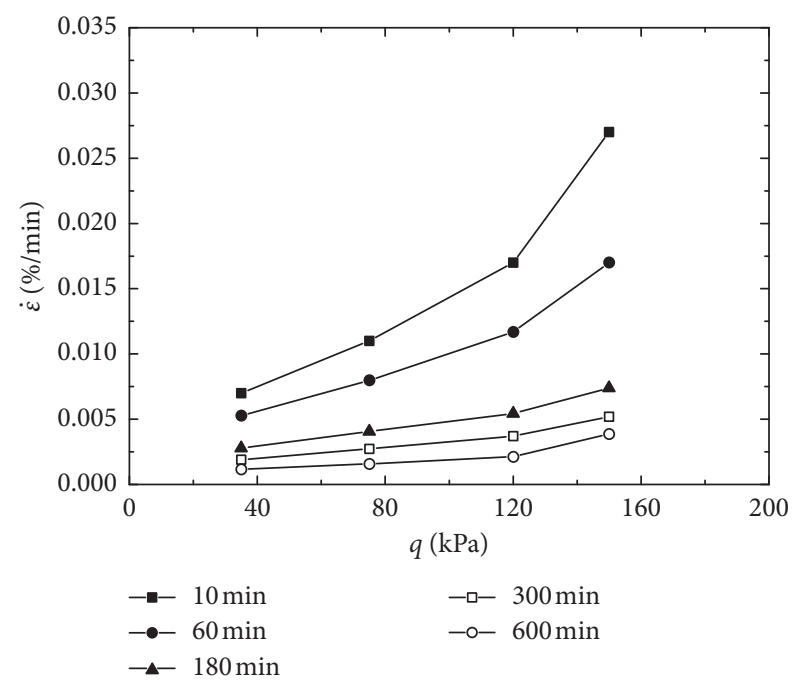

Figure 11: $\dot{\varepsilon}_{\mathrm{a}}$ versus $q$ under $100 \mathrm{kPa}$ cell pressure.
Mesri creep equation to describe the stress-strain-time relationship of the Dalian IMT clays based on the triaxial creep test results. The Mesri creep equation is as follows:

$$
\varepsilon=\frac{2}{E_{\mathrm{u}} / S_{\mathrm{u}}} \cdot \frac{\bar{D}}{1-R_{\mathrm{f}} \overline{\bar{D}}}\left(\frac{t}{t_{1}}\right)^{\lambda},
$$

where $\varepsilon$ is the axial strain, $t$ is the creep time, $E_{\mathrm{u}}$ is the initial tangent modulus, $S_{\mathrm{u}}$ is the shear strength, $\bar{D}$ is the shear stress level $\left(\bar{D}=\left(\sigma_{1}-\sigma_{3}\right) /\left(\sigma_{1}-\sigma_{3}\right)_{\mathrm{f}}\right), R_{\mathrm{f}}$ is the failure stress ratio, $t_{1}$ is the reference time, and $\lambda$ is the test constant.

When $t=t_{1}$, equation (7) can be expressed as follows:

$$
\frac{\varepsilon}{\bar{D}}=\frac{2}{E_{\mathrm{u}} / S_{\mathrm{u}}}+R_{\mathrm{f}} \varepsilon,
$$

where $2 /\left(E_{\mathrm{u}} / S_{\mathrm{u}}\right)$ and $R_{\mathrm{f}}$ are the intercept and slope of the $(\varepsilon / \bar{D})-\varepsilon$ curve, respectively, and $\lambda$ is the slope of the $\lg \varepsilon-\lg \left(t / t_{1}\right)$ curve.

The Mesri creep equation contains three parameters, namely, $2 /\left(E_{\mathrm{u}} / S_{\mathrm{u}}\right), R_{\mathrm{f}}$, and $\lambda$, all of which can be determined by the regression analysis of test result.

6.2. Establishing the Model. The creep test results obtained for the silty clay collected at a depth of $26 \mathrm{~m}$ and $30 \mathrm{~m}$ under cell pressures of $100 \mathrm{kPa}$ and $200 \mathrm{kPa}$ are used as examples to demonstrate how the Mesri model parameters are determined. Figure 12 shows the fitting results (reference time: $10 \mathrm{~h}$ ) that indicate a basically linear relationship between $\varepsilon / \bar{D}$ and $\varepsilon$ under cell pressures of 100 and $200 \mathrm{kPa}$, which with a correlation coefficient greater than 0.98 . In addition, there was also a linear relationship between $\varepsilon$ and $t / t_{1}$ in the log-log plot, which with a correlation coefficient greater than 0.88 . Table 5 summarizes the Mesri model parameters for the silty clay samples collected at depths of 26 and $30 \mathrm{~m}$ under cell pressures of 100 and $200 \mathrm{kPa}$, which determined by regression analysis.

It is worth noting that the fitting results for the failure deviatoric stress are not shown in Figure 12. In view of this, the creep process under the action of the failure deviatoric stress was subjected to fitting analysis using the method of least squares. A relatively high goodness of fit was achieved when using a cubic polynomial. Therefore, based on the concept of piecewise functions, the Mesri equation was coupled with a cubic polynomial to describe the clay creep process. The Mesri equation was used for simulations in which the deviatoric stress was less than the failure deviatoric stress. A cubic polynomial was used for simulations in which the deviatoric stress was equal to or greater than the failure deviatoric stress. The model is represented by the following equation:

$$
\begin{cases}\varepsilon=\frac{2}{E_{\mathrm{u}} / S_{\mathrm{u}}} \cdot \frac{\bar{D}}{1-R_{\mathrm{f}} \bar{D}}\left(\frac{t}{t_{1}}\right)^{\lambda}, & \bar{D}<1, \\ \varepsilon=a t^{3}+b t^{2}+c t+d, & \bar{D}=1 .\end{cases}
$$

Table 6 summarizes the model parameters determined by fitting the creep test results of the silty clay at depths of 26 and $30 \mathrm{~m}$, using a cubic polynomial. 

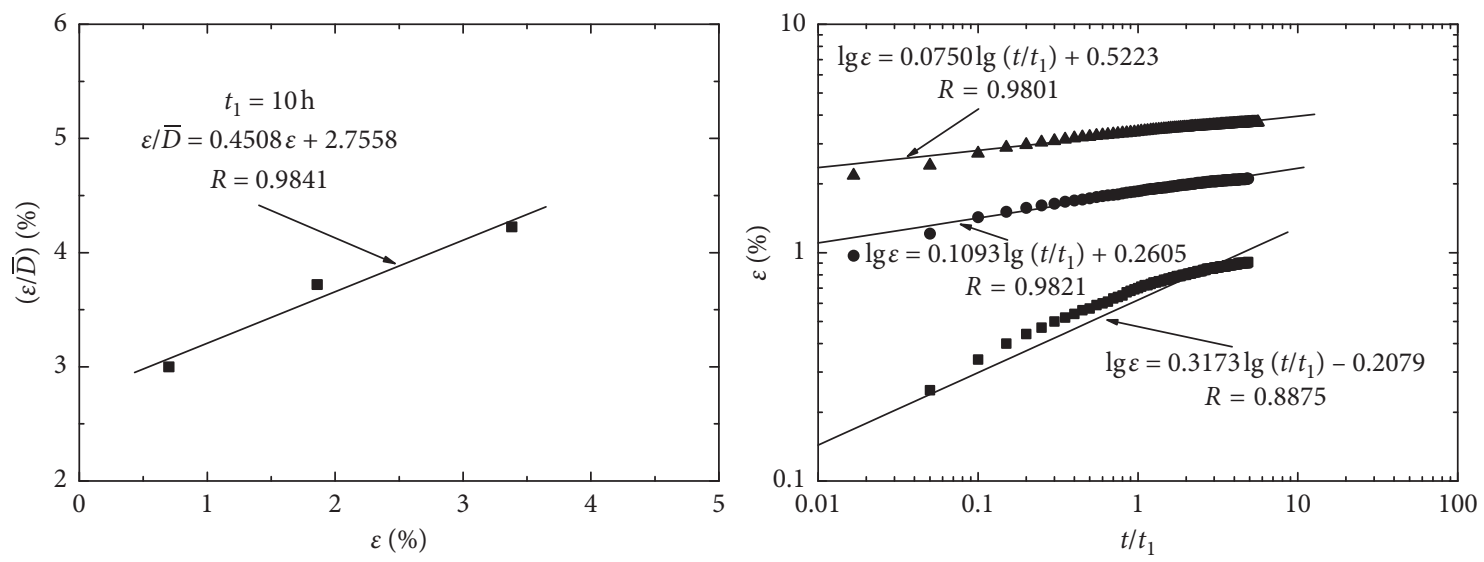

- $120 \mathrm{kPa}$

- $75 \mathrm{kPa}$

- $35 \mathrm{kPa}$

(a)
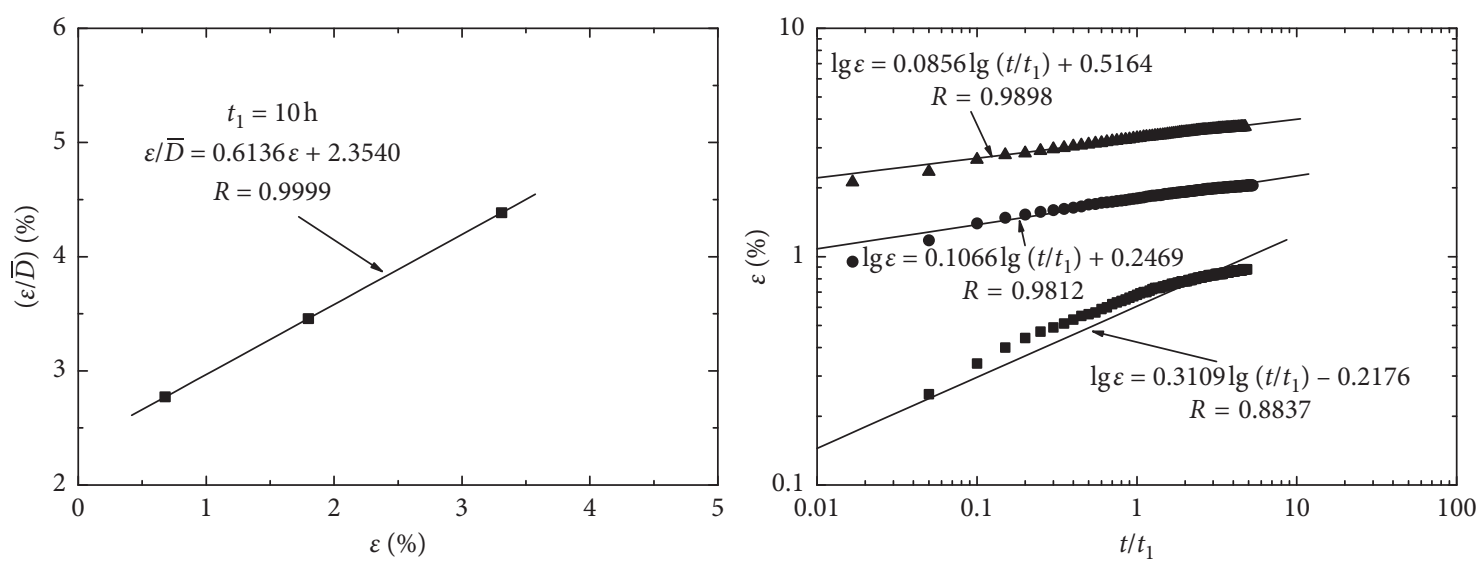

- $200 \mathrm{kPa}$

- $138 \mathrm{kPa}$

- $65 \mathrm{kPa}$

(b)

Figure 12: Fitting parameters of Mesri model under different cell pressures. (a) $100 \mathrm{kPa}$ and (b) $200 \mathrm{kPa}$.

TABLe 5: Mesri model parameters.

\begin{tabular}{|c|c|c|c|c|c|c|c|}
\hline Depth (m) & $\sigma_{3}(\mathrm{kPa})$ & $\left(\sigma_{1}-\sigma_{3}\right)_{\mathrm{f}}(\mathrm{kPa})$ & $t_{1}(\mathrm{~h})$ & $\bar{D}$ & $2 /\left(E_{\mathrm{u}} / S_{\mathrm{u}}\right)$ & $(R)_{\mathrm{f}}$ & $\lambda$ \\
\hline \multirow{6}{*}{26} & \multirow{4}{*}{100} & \multirow{3}{*}{150} & \multirow{3}{*}{10} & 0.2333 & 2.7558 & 0.4508 & 0.3173 \\
\hline & & & & 0.5000 & 2.7558 & 0.4508 & 0.1093 \\
\hline & & & & 0.8000 & 2.7558 & 0.4508 & 0.0750 \\
\hline & & \multirow{3}{*}{265} & \multirow{3}{*}{10} & 0.2453 & 2.3540 & 0.6136 & 0.3109 \\
\hline & \multirow[t]{2}{*}{200} & & & 0.5208 & 2.3540 & 0.6136 & 0.1066 \\
\hline & & & & 0.7547 & 2.3540 & 0.6136 & 0.0856 \\
\hline \multirow{6}{*}{30} & \multirow{4}{*}{100} & \multirow{3}{*}{183} & \multirow{3}{*}{10} & 0.2732 & 4.9351 & 0.2289 & 0.1825 \\
\hline & & & & 0.5464 & 4.9351 & 0.2289 & 0.0958 \\
\hline & & & & 0.8470 & 4.9351 & 0.2289 & 0.0646 \\
\hline & & \multirow{3}{*}{345} & \multirow{3}{*}{10} & 0.2667 & 2.8648 & 0.4555 & 0.1425 \\
\hline & \multirow[t]{2}{*}{200} & & & 0.5420 & 2.8648 & 0.4555 & 0.0997 \\
\hline & & & & 0.8116 & 2.8648 & 0.4555 & 0.0611 \\
\hline
\end{tabular}

6.3. Verifying the Model. The newly established model was used to calculate the creep process of the silty clay collected at depths of 26 and $30 \mathrm{~m}$ under cell pressures of 100 and $200 \mathrm{kPa}$. Figure 13 shows the comparison which indicates that the calculated results obtained using the Mesri model under cell pressures of 100 and $200 \mathrm{kPa}$ matched the test results relatively well. The calculation results obtained using the polynomial can relatively well describe the accelerated creep 
TABle 6: Polynomial model parameters.

\begin{tabular}{lccccrr}
\hline Depth $(\mathrm{m})$ & $\sigma_{3}(\mathrm{kPa})$ & $\bar{D}$ & $a$ & $b$ & $c$ & \multicolumn{1}{c}{$c$} \\
\hline \multirow{2}{*}{26} & 100 & 1 & 0.0054 & -0.0882 & 0.5448 & 1.1375 \\
& 200 & 1 & 0.0442 & -0.3451 & 3.6136 \\
\hline \multirow{2}{*}{30} & 100 & 1 & 0.0570 & -0.2180 & 0.3130 & 5.4140 \\
& 200 & 1 & 0.0730 & -0.4540 & 1.3100 & 3.8030 \\
\hline
\end{tabular}

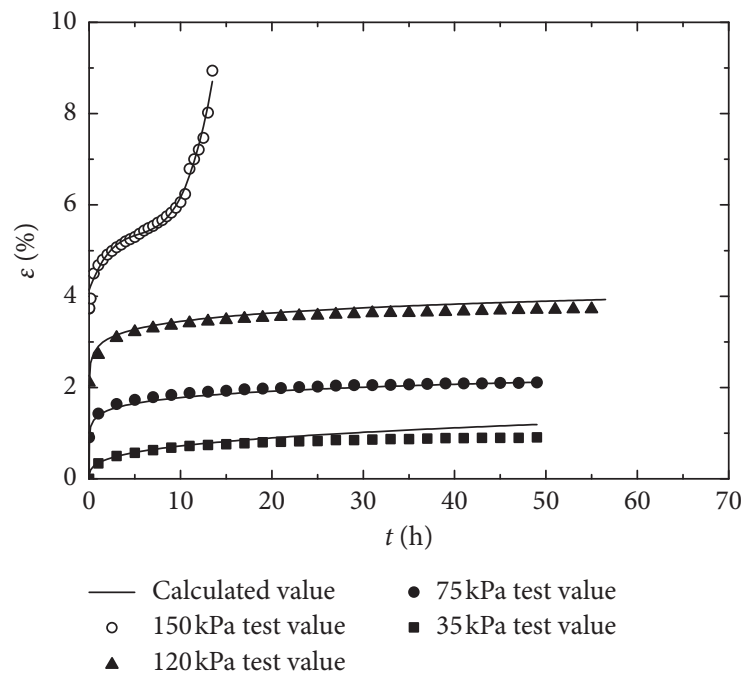

(a)

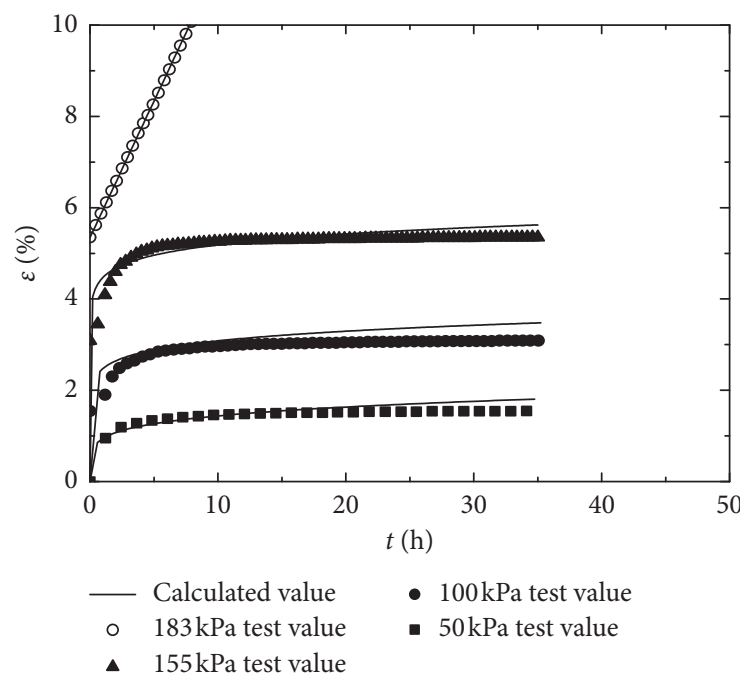

(c)

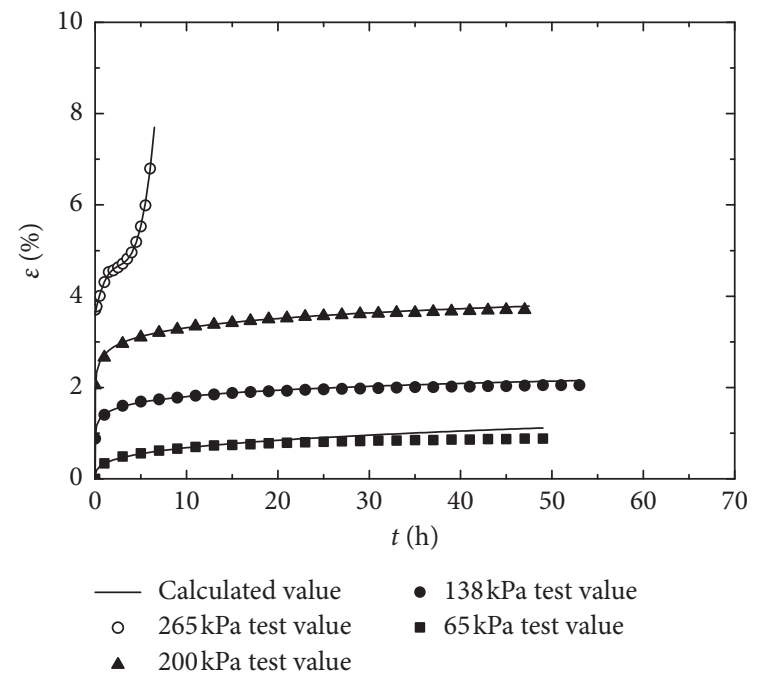

(b)

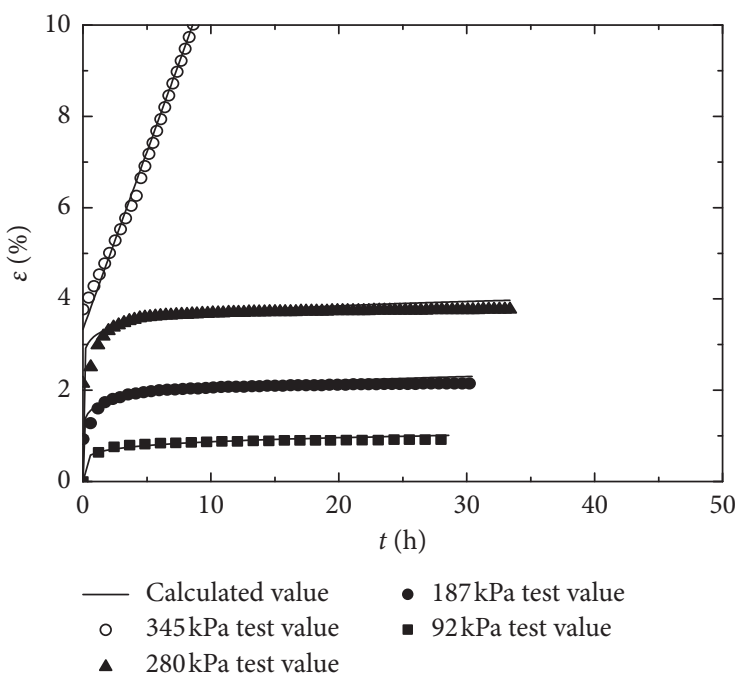

(d)

FIGURE 13: Test results compared with calculation results at different depths and cell pressures. (a) $26 \mathrm{~m} \mathrm{depth}$ and $100 \mathrm{kPa}$, (b) $26 \mathrm{~m}$ depth and $200 \mathrm{kPa}$, (c) $30 \mathrm{~m}$ depth and $100 \mathrm{kPa}$, and (d) $30 \mathrm{~m}$ depth and $200 \mathrm{kPa}$.

process. The relative difference between the calculation and test results was small. The high degree of consistency between the test and calculation results validates the reliability of the newly established model and indicates its suitability for describing the creep behavior of Dalian IMT clay.

\section{Conclusions}

The creep behavior of Dalian IMT clay was studied using 1D and triaxial drained creep tests. Based on the creep test results, a $1 \mathrm{D}$ creep equation in the form of a power function and a three-dimensional (3D) creep equation consisting of the Mesri equation and a cubic polynomial were established. The conclusions are summarized as follows:

(1) As the consolidation time and pressure increased, the strain of the Dalian IMT deposits increased, whereas the void ratio decreased. The clays basically entered the stage of secondary consolidation and deformation after the action of consolidation pressure at all levels over $100 \mathrm{~min}$. 
(2) The Dalian IMT deposits exhibited typical nonlinear creep behavior. Their creep behavior became increasingly pronounced as the consolidation pressure increased. The secondary consolidation coefficient of the clays was related to the consolidation pressure. The ratio of the secondary consolidation coefficient to the compression index was consistent with the conclusion derived by Mesri.

(3) The Dalian IMT clays exhibited typical nonlinear creep behavior. The clays displayed shear contraction behavior under the action of a low deviatoric stress and shear contraction and shear dilation behavior under the action of the failure deviatoric stress.

(4) The axial strain rate decreased with creep time and increased with increasing deviatoric stress. The deviatoric stress had a relatively insignificant impact on the $m$-value. Under the action of a low deviatoric stress, the creep rate gradually decreased with creep time, and the clays displayed attenuation creep behavior. Under the action of the failure deviatoric stress, the creep rate first decreased and then increased with creep time, and the clays exhibited attenuation and acceleration creep behavior.

(5) There was a relatively high degree of consistency between the test results and the calculation results, which validating the newly established model. This suggests that both the $1 \mathrm{D}$ and $3 \mathrm{D}$ creep equations are suitable for describing the creep behavior of Dalian IMT clay and can provide guidance for predicting long-term foundation deformation.

\section{Data Availability}

The data used to support the findings of this study are available from the corresponding author upon request.

\section{Conflicts of Interest}

The authors declare that there are no conflicts of interest regarding the publication of this paper.

\section{Acknowledgments}

This study was supported by the Special Fund for Scientific Research by Xijing University (XJ18T01), Special Fund for Scientific Research by Shaanxi Provincial Education Department (18JK1199), and the Fundamental Research Funds for the Central Research Institutes (TKS170102 and TKS170108).

\section{References}

[1] Z. B. Liu, S. Y. Liu, B. M. Zhou et al., "Geological genesis and spatial variability characteristic of the interactive marine and terrestrial soft deposit in Yangtze River estuary," Chinese Journal of Underground Space and Engineering, vol. 10, no. 1, pp. 102-108, 2014.
[2] X. P. Chen, "Consolidation effect of soft soil in interactive marine and terrestrial deposit," Chinese Journal of Geotechnical Engineering, vol. 33, no. 4, pp. 520-528, 2011.

[3] Y. H. Liu and M. L. Shi, "Evaluation research and distinguishing of cohesive soil properties in the interactive marine \& terrestrial deposit," Rock and Soil Mechanics, vol. 29, no. 2, pp. 523-528, 2008.

[4] H. Zhang, Y. H. Liu, M. L. Shi et al., "Research of characteristics of the sedimentary clay in the alternate marine and terrigenous environment," Rock and Soil Mechanics, vol. 26, no. 9, pp. 1491-1494, 2005.

[5] Z. B. Liu, S. Y. Liu, F. Jing et al., "Pore pressure response of composite foundation in interactive marine and terrestrial deposit of Yangtze River estuary," Chinese Journal of Geotechnical Engineering, vol. 37, no. S2, pp. 91-95, 2015.

[6] Y. F. Tuo, L. W. Kong, A. G. Guo et al., "Occurrence and engineering properties of structural soft clay in Zhanjiang area," Rock and Soil Mechanics, vol. 25, no. 12, pp. 1879-1884, 2004.

[7] M. L. Shi, B. Zhang, and Z. S. Hong, "Mechanical properties of natural sedimentary intermediate soils," Rock and Soil Mechanics, vol. 26, no. 11, pp. 1753-1756, 2005.

[8] J.-H. Yin, "Non-linear creep of soils in oedometer tests," Géotechnique, vol. 49, no. 5, pp. 699-707, 1999.

[9] C. W. W. Ng, Q. Li, and G. B. Liu, "Characteristics of onedimensional compressibility of Shanghai clay," Chinese Journal of Geotechnical Engineering, vol. 33, no. 4, pp. 630636, 2011.

[10] G. Mesri and P. M. Godlewski, "Time and stress compressibility interrelationship," Journal of Geotechnical Engineering, vol. 103, no. 5, pp. 417-430, 1979.

[11] X. C. Shi, R. Wang, and Z. X. Zhang, "Study on secondary consolidation properties of Guangxi marine ooze," Rock and Soil Mechanics, vol. 24, no. 5, pp. 863-865, 2003.

[12] H. M. Zhang, Y. S. Xu, and Q. L. Zeng, "Deformation behavior of Shenzhen soft clay and post-construction settlement," Chinese Journal of Geotechnical Engineering, vol. 24, no. 4, pp. 509-514, 2002.

[13] L. C. Miao, J. H. Zhang, and Y. N. Chen, "Study on compressibility of Jiangsu marine clay," Chinese Journal of Geotechnical Engineering, vol. 29, no. 11, pp. 1711-1714, 2007.

[14] F. Z. Zhang, X. P. Chen, and G. Y. Huang, "Experimental investigation of consolidation behavior of the pearl delta saturated soft clay," Rock and Soil Mechanics, vol. 24, pp. 192-194, 2003.

[15] Q. J. Zhou and X. P. Chen, "Test study on properties of secondary consolidation of soft soil," Rock and Soil Mechanics, vol. 27, no. 3, pp. 404-408, 2006.

[16] P. Z. Lu, J. Zeng, and Q. Sheng, "Creep tests on soft clay and its empirical models," Rock and Soil Mechanics, vol. 29, no. 4, pp. 1041-1045, 2008.

[17] H. Y. Lei, J. J. Liu, Y. F. Jia et al., "Triaxial test on creep properties of coastal soft clay," Journal of Tianjin University (Science and Technology), vol. 46, no. 5, pp. 387-392, 2013.

[18] Y. K. Liu, Z. B. Deng, P. Cao et al., "Triaxial creep test and modified Singh-Mitchell creep model of soft clay," Journal of Central South University (Science and Technology), vol. 43, no. 4, pp. 1440-1446, 2012.

[19] X. L. Lai, S. M. Wang, W. M. Ye, and Y. J. Cui, "Experimental investigation on the creep behavior of an unsaturated clay," Canadian Geotechnical Journal, vol. 51, no. 6, pp. 621-628, 2014.

[20] L. Z. Wang and Z. Y. Yin, "Stress dilatancy of natural soft clay under an undrained creep condition," International Journal of Geomechanics, vol. 15, no. 5, pp. 1-5, 2015. 
[21] S. W. Yan, K. J. Liu, W. Li et al., "Study of creep properties of soft clay in Tianjin Binhai new area and no-yield-surface constitutive model," Rock and Soil Mechanics, vol. 31, no. 5, pp. 1431-1436, 2010.

[22] M.-Q. Sun, Q. Wang, C.-C. Niu, and T. Sun, "Research on the one-dimensional rheological consolidation theory that considers secondary consolidation effect," Journal of Computational and Theoretical Nanoscience, vol. 13, no. 2, pp. 1136-1146, 2016.

[23] Y.-b. Zhu and H.-m. Yu, "An improved Mesri creep model for unsaturated weak intercalated soils," Journal of Central South University, vol. 21, no. 12, pp. 4677-4681, 2014.

[24] S.-y. Feng, L.-m. Wei, C.-y. He, and Q. He, "A computational method for post-construction settlement of high-speed railway bridge pile foundation considering soil creep effect," Journal of Central South University, vol. 21, no. 7, pp. 29212927, 2014.

[25] M.-j. Jiang, J.-d. Liu, and Z.-y. Yin, "Consolidation and creep behaviors of two typical marine clays in China," China Ocean Engineering, vol. 28, no. 5, pp. 629-644, 2014.

[26] M. Q. Sun, Q. Wang, Y. K. Ruan et al., "Settlement prediction of soft soil foundation based on consolidation and creep theory," International Journal of Simulation: System, Science and Technology, vol. 16, no. 2, pp. 21-28, 2015.

[27] A. M. Shaban and P. J. Cosentino, "Modeling long-term deformations of unbound pavement materials using the miniaturized preburemeter creep data," Geotechnical Testing Journal, vol. 39, no. 5, pp. 813-826, 2016.

[28] A. Singh and J. K. Mitchell, "General stress-strain-time function for soils," Journal of the Soil Mechanics and Foundation Divisions, vol. 94, no. 1, pp. 21-46, 1968.

[29] G. Mesri, E. Febres-Cordero, D. R. Shields, and A. Castro, "Shear stress-strain-time behaviour of clays," Géotechnique, vol. 31, no. 4, pp. 537-552, 1981. 


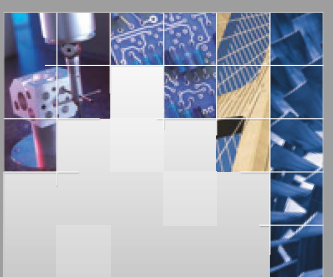

\section{Enfincering}
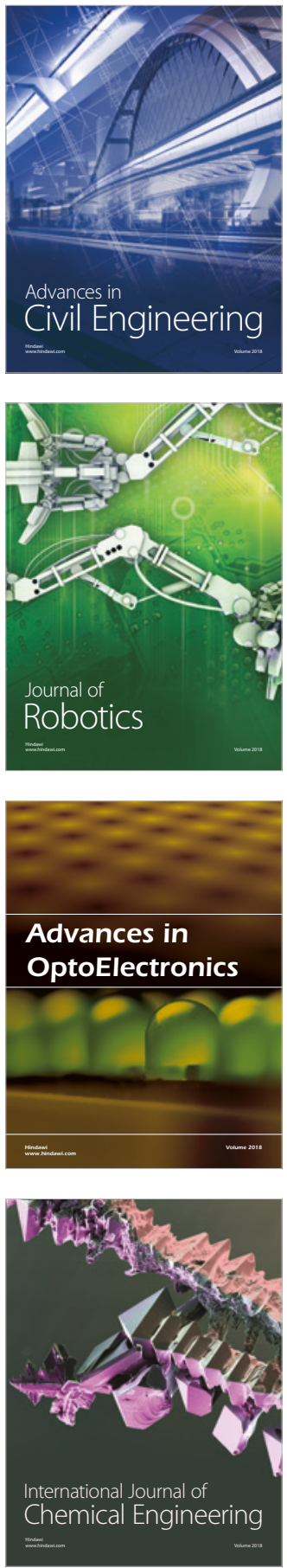

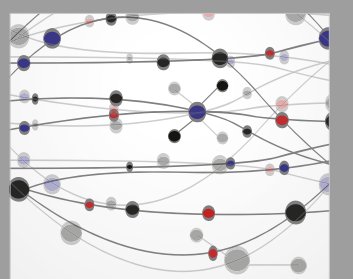

\section{Rotating \\ Machinery}

The Scientific World Journal

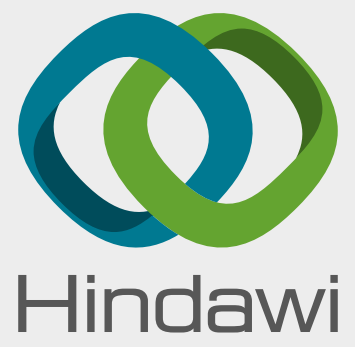

Submit your manuscripts at

www.hindawi.com
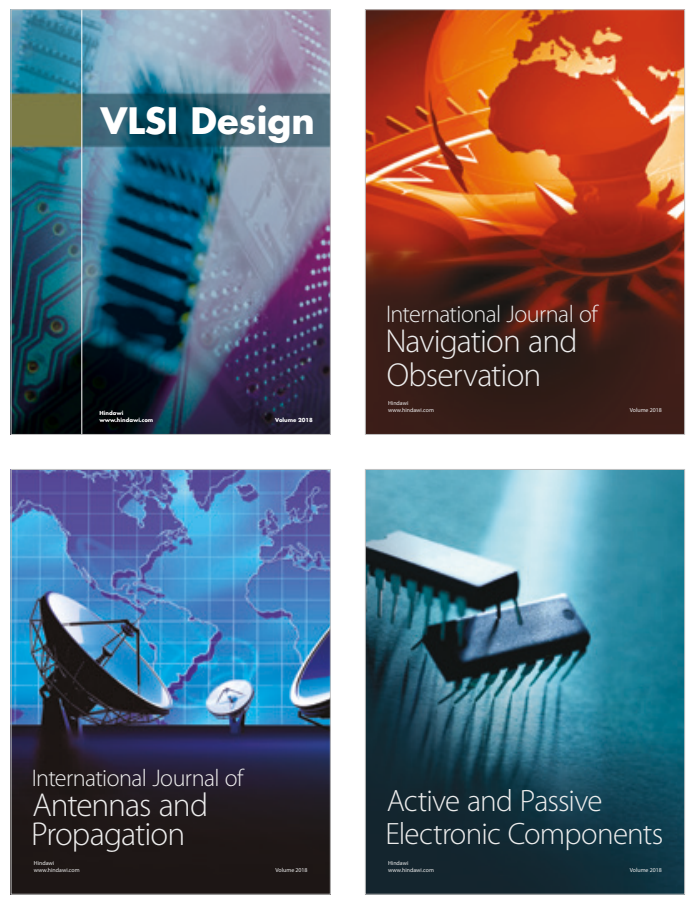
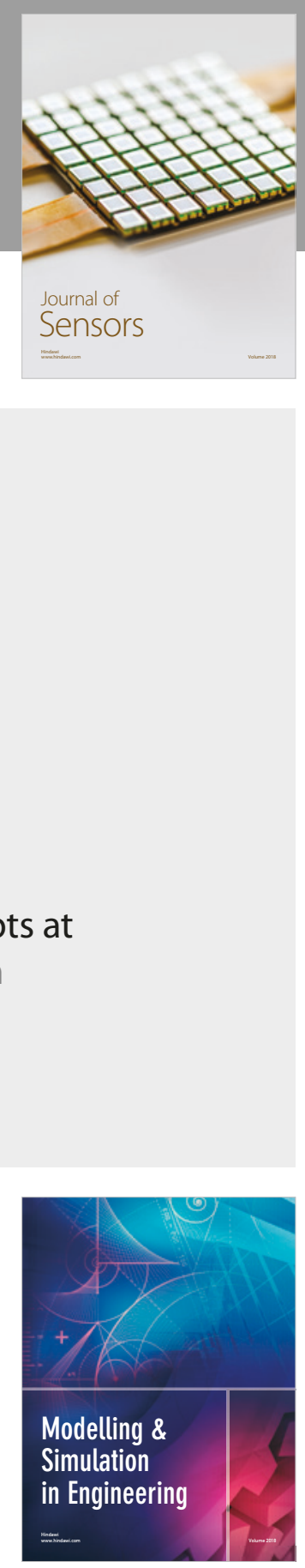

\section{Advances \\ Multimedia}
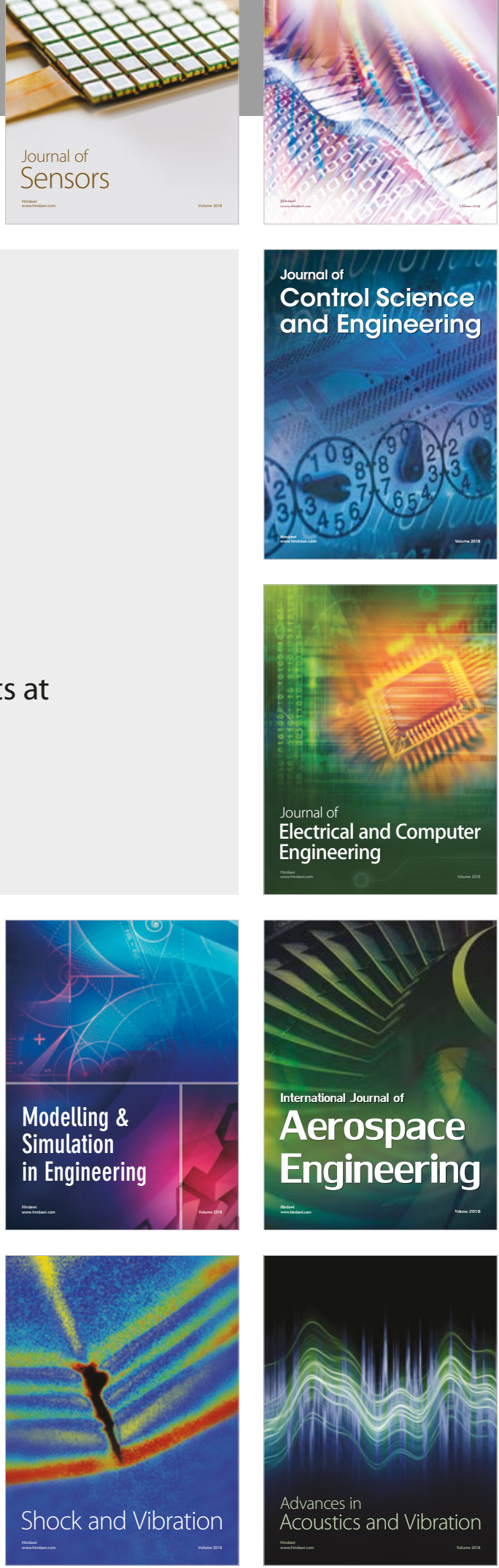